Journal for

ImmunoTherapy of Cancer

\title{
Tumor-associated macrophages: potential therapeutic strategies and future prospects in cancer
}

Chunxiao Li ${ }^{10},{ }^{1}$ Xiaofei Xu, ${ }^{2,3}$ Shuhua Wei, ${ }^{1}$ Ping Jiang, ${ }^{1}$ Lixiang Xue, ${ }^{1}$ Junjie Wang ${ }^{1}$

To cite: Li C, Xu X, Wei S, et al. Tumor-associated macrophages: potential therapeutic strategies and future prospects in cancer. Journal for ImmunoTherapy of Cancer 2021;9:e001341. doi:10.1136/jitc-2020-001341

\section{$\mathrm{CL}, \mathrm{XX}$ and SW are joint first} authors.

Accepted 06 December 2020

\section{Check for updates}

(C) Author(s) (or their employer(s)) 2021. Re-use permitted under CC BY-NC. No commercial re-use. See rights and permissions. Published by BMJ.

${ }^{1}$ Department of Radiation Oncology, Peking University Third Hospital, Beijing, China ${ }^{2}$ Center for Reproductive Medicine, Department of Obstetrics and Gynecology, Peking University Third Hospital, Beijing, China

${ }^{3}$ Department of Obstetrics and Gynecology, Beijing Tsinghua Changgung Hospital, School of Clinical Medicine, Tsinghua University, Beijing, China

Correspondence to

Dr Chunxiao Li;

chunxiaoli@pku.edu.cn

Dr Ping Jiang;

drjiangping@qq.com

Dr Lixiang Xue;

lixiangxue@bjmu.edu.cn

Dr Junjie Wang;

junjiewang_edu@sina.cn

\section{ABSTRACT}

Macrophages are the most important phagocytes in vivo. However, the tumor microenvironment can affect the function and polarization of macrophages and form tumorassociated macrophages (TAMs). Usually, the abundance of TAMs in tumors is closely associated with poor prognosis. Preclinical studies have identified important pathways regulating the infiltration and polarization of TAMs during tumor progression. Furthermore, potential therapeutic strategies targeting TAMs in tumors have been studied, including inhibition of macrophage recruitment to tumors, functional repolarization of TAMs toward an antitumor phenotype, and other therapeutic strategies that elicit macrophage-mediated extracellular phagocytosis and intracellular destruction of cancer cells. Therefore, with the increasing impact of tumor immunotherapy, new antitumor strategies to target TAMs are now being discussed.

\section{INTRODUCTION}

Macrophages are the most important phagocytes in vivo and play a role in engulfing cellular debris, bacteria, intracellular parasites, aging and abnormal cells, cancer cells and apoptotic cells. ${ }^{1}$ Macrophages exist in nearly all tissues and organs (figure 1) and serve as the first line of defense against exogenous and endogenous damage-associated molecular patterns (DAMPs) or pathogenassociated molecular patterns. ${ }^{2}$ In 1883 , Elie Metchnikoff published a key paper describing phagocytic cells in frogs. His descriptions were not only about phagocytes involved in host defense, but also described how these specialized cells eliminated degenerating or dying cells of the very same host during metamorphosis. ${ }^{3}$ In 1905, his findings suggested that macrophages from infected animals could promote the ability of killing bacteria, thereby proposing the basis of the concept of macrophage activation. ${ }^{4}$ Thus, the mechanisms by which macrophages kill bacteria have been gradually revealed after six decades of research. ${ }^{56}$ In the 1930s, Ebert and Florey found that monocytes in the blood migrated to different tissues and organs to differentiate into macrophages. ${ }^{7}$ In 1968, researchers discovered the presence of macrophage precursor cells in bone marrow, a discovery that further developed the mononuclear phagocyte system theory, which was confirmed and put forward formally as the first systematic theory on the origin of macrophages in $1972 .{ }^{89}$ North and Mackaness found that cytokines alone could cause inflammation even in the absence of pathogens. ${ }^{10}$ Rosenstreich et al also found that lymphocytes are the most important cells causing the antimicrobial response of macrophages. ${ }^{11}$ Subsequently, the role of interferon- $\gamma($ IFN- $\gamma)$ secreted by lymphocytes as a bridge between lymphocytes and macrophages was discovered, as was the transformation of resting macrophages to macrophages with increased antibacterial and regulatory phagocytosis capacities and secretion of proinflammatory cytokines; macrophages with this activated phenotype were officially named 'classically activated macrophages' or M1 macrophages, and this recognition of macrophage subtypes represented a first and important step in the study of macrophage polarization. ${ }^{12}$ Over the next 30 years, the study of macrophage polarization made rapid progress. In 1989, with the finding of Th1 and Th2 cells, it was found that interleukin-4 (IL-4) secreted by Th2 cells could polarize macrophages into a phenotype different from the M1 type. ${ }^{13}$ When macrophages are activated by IL- 4 , their respiratory burst is suppressed, and the expression of Major Histocompatibility Complex (MHC) II is enhanced significantly; concomitant upregulation of the mannose receptor was proved in later studies. ${ }^{14}$ Combined with these characteristics, the concept of 'alternatively activated macrophages' was first proposed in 1992. ${ }^{15}$ Based on the plasticity and adaptability of macrophages in response to different environments, Mosser and Edwards proposed that M1 and M2 were the two extremes in 


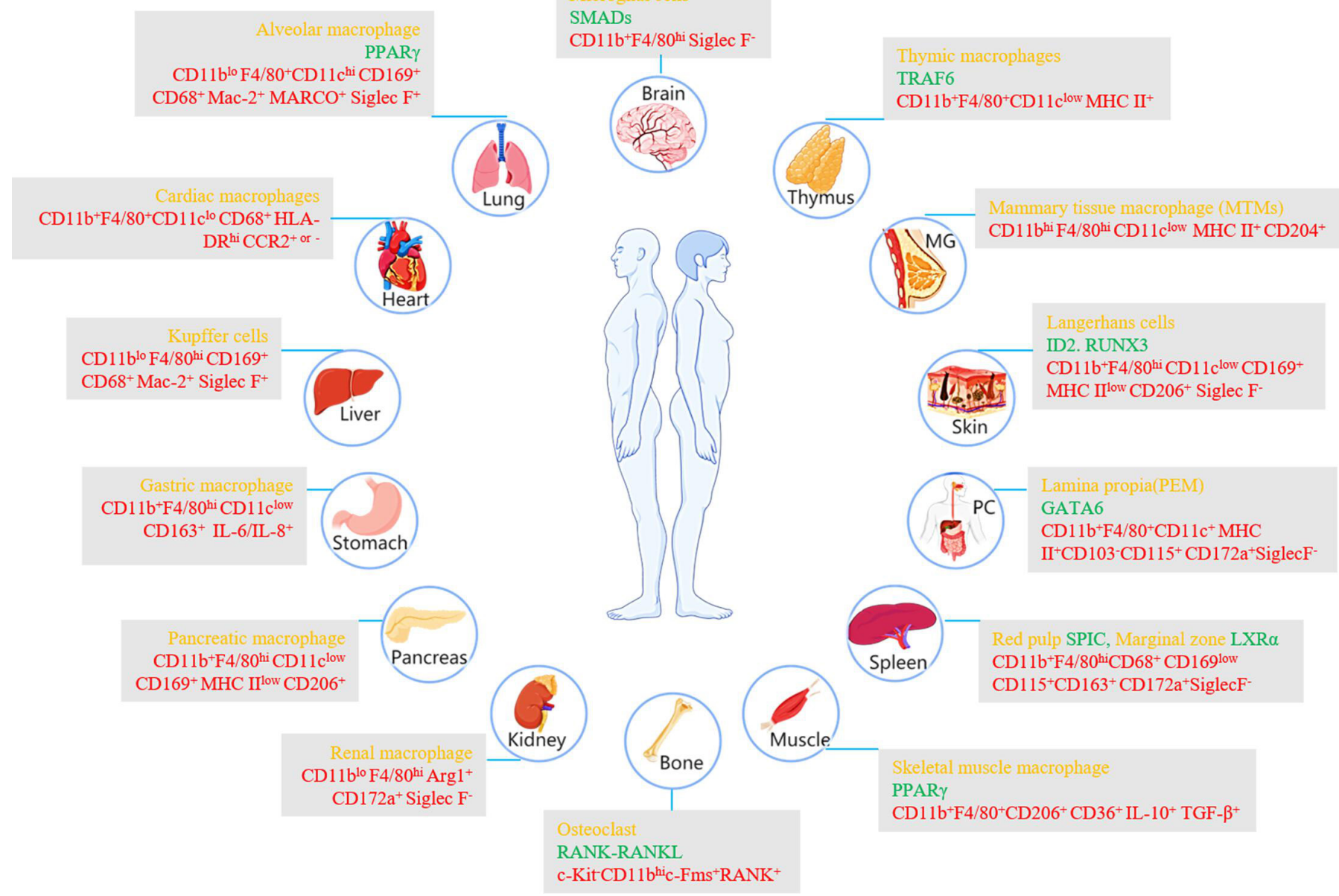

Figure 1 The distribution of macrophages in different tissues and organs. Macrophages are heterogeneous, showing different names, specific transcription factors and markers. Here, different colors correspond to different items, yellow for names, green for transcription factors and red for markers. IL-6, interleukin 6; MG, mammary gland; PC, peritoneal cavity; TGF- $B$, transforming growth factor- $\beta$.

the polarization process of macrophages. ${ }^{16}$ In 2010, the concept of macrophage polarization was modified again with the presentation of M2-like macrophages that were stimulated to transform into yet different phenotypes by immune complexes (M2b phenotype) or IL-10, transforming growth factor- $\beta$ (TGF- $\beta$ ), and glucocorticoids
(M2c phenotype), among others. ${ }^{17}$ These special environmental factors trigger switches in the phenotype and function of macrophages, allowing them to play different roles under different stimuli and to change dynamically between the two extremes of the M1 and M2 phenotypes ${ }^{18}$ (figure 2).

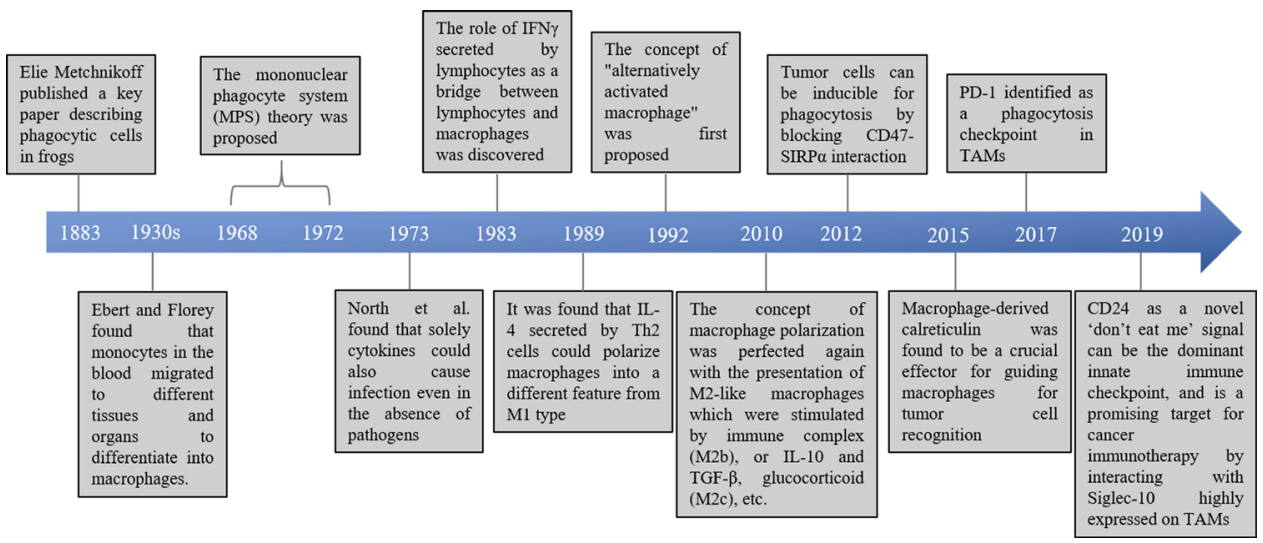

Figure 2 History of macrophages in cancer. Advances made over the past decades in the identification of macrophages including checkpoints and stimulatory signals. IFN $\gamma$, interferon- $\gamma$; IL-10, interleukin 10; PD-1, programmed cell death protein 1; $\operatorname{SIRP} \alpha$, signal regulatory protein $\alpha$; TAMs, tumor-associated macrophage; TGF- $\beta$, transforming growth factor- $\beta$. 


\section{Macrophage origin}

Macrophages exist in nearly all healthy adult tissues, deriving from either an embryonic precursor (yolk sac or fetal liver) before birth or a monocyte precursor of hematopoietic origin in adults. ${ }^{19}{ }^{20}$ In the brain, lung and liver, embryonically derived macrophages can be maintained by self-renewal of tissue-resident macrophages in adults, while in the gut, skin, heart and pancreas, most subsets are progressively maintained through the differentiation of monocyte precursors from hematopoietic stem cells (HSCs). ${ }^{21}$ During myocardial infarction, cardiac-resident macrophages can be replenished by monocytes. ${ }^{22-25}$ The Ly6 $\mathrm{C}^{\text {high }}$ monocyte cells are plentifully recruited to the infarct area from the bone marrow and spleen through monocyte chemoattractant protein-1 (MCP-1)/CCR2 chemokine receptor interaction. ${ }^{26-29}$ However, the Ly6 $\mathrm{C}^{\text {low }}$ monocytes are recruited through CX3 chemokine receptor 1 (CX3CR1) into the infarcted area. ${ }^{29}$

Due to the development of labeling of single cells for in vivo cell fate mapping, research on the origin of tissueresident macrophages (TRMs) has seen recent advances. ${ }^{30}$ Studies have shown that TRMs exist during embryonic development and are independent of the circulating monocytes in the blood. In the first trimester, macrophages first appear in the yolk sac between embryonic day 6.5 and embryonic day 8.5 (E6.5-E8.5). Then (E8.5E10.5), HSCs appear in the aorta-gonad-mesonephros region and determine the immune cell lineages. At E10.5, HSCs migrate to the fetal liver, which becomes the main hematopoietic organ during subsequent embryonic development. ${ }^{31}$ Until the perinatal stage, traditional bone marrow stem cells are the predominant hematopoietic cells and complement the immune cell lineages. All adult macrophages, resident or infiltrating, are progenies of classical HSCs with the exception of microglia and some epidermal Langerhans cells, which are yolk sac-derived. ${ }^{32}$ We consider blood monocytes as tissue-macrophage progenitors because the major fraction of macrophages originates from blood-borne monocytes. Under specific circumstances, the egress of monocytes from blood to inflamed tissue is dependent on both CCR2 and CX3CR $1 .{ }^{33}$ Defining the origins and developmental pathways of TRMs should help refine our understanding of the role of these cells in various disease settings. However, the exact differentiation pathways of the embryonic progenitors that give rise to adult TRMs are still controversial, and the mechanisms of macrophage maintenance in adult tissue are undefined. Tumor-associated macrophages (TAMs) mainly originate from bone-marrowderived monocytes ${ }^{34-36}$ although local proliferation has been observed in some mouse tumors. ${ }^{37}$ Chemokines (eg, CCL2 (MCP-1), CCL3 (macrophage inflammatory protein (MIP) $1 \alpha$ ), CCL4 (MIP1 $\beta$ ) and CXCL12 (stromal cell-derived factor $1 \alpha$ )) and colony-stimulating factor (CSF-1) are major determinants of monocyte infiltration in tumor microenvironment (TME), as well as IL-6 and IL-1 $\beta$, and vascular epidermal growth factor A (VEGFA).$^{38}$ Besides, the complement cascade also have been described to have a role in recruiting macrophage. ${ }^{40}{ }^{41}$ In these cases, the major recruitment factor is the chemokine CCL2, produced mostly by tumor cells, which acts through CCR2 expressed on classical monocytes. ${ }^{34} 38$ 42-44 However, other studies suggest that in pancreatic cancer and glioma, TAMs can also originate from yolk sac and fetal liver, ${ }^{45-50}$ both recruited monocyte-derived TAMs (MoD-TAMs) and tissue-resident interstitial TAMs (Res-TAMs) can acquire different functions depending on cancer type. In humans, the breast and endometrial TAMs have a completely different transcriptional landscape and marker profile from TRMs and from each other, ${ }^{51}$ suggesting that different niches can activate TAMs in a tumor-specific and tissue-specific way. These observations reinforce the idea that the TAMs definition should not be used just to identify bone marrowderived macrophages that infiltrate the tumor, but it should be extended to all macrophages that play a role within the TME, including TRMs. ${ }^{52}$ Res-TAMs in mouse lungs contribute to the pool of TAMs together with CCR2-dependent recruited MoD-TAMs. Res-TAMs largely correlate with tumor growth, while MoD-TAMs accumulation is associated with enhanced tumor spreading. Both subsets can be depleted after chemotherapy, but MoD-TAMs rapidly recover and perform phagocytosismediated tumor clearance. ${ }^{53}$ Therefore, in a particular tumor, understanding the origin, function and types of TAMs is critical to the selection of targeting TAMs strategies.

\section{Functional classifications}

In contrast with the MPS theory, the current dominant view is that macrophages can be divided into two functional categories: classically activated macrophages (M1) and alternatively activated macrophages (M2), which work on two major lymphocyte subpopulations, Th1 and Th2 cells and have diametrically contrasting functions according to the pattern of cytokines they secrete (figure 3). M1 macrophages, also known as inflammatory macrophages, are mainly activated by IFN- $\gamma$ secreted by Th1 cells, Cytotoxic T Lymphocytes (CTLs) and natural killer (NK) cells; TNF- $\alpha$; HMGB1 $1^{54}$; lipopolysaccharide (LPS), ${ }^{55}$ a component of the outer membrane of Gram-negative bacteria and granulocyte-macrophage CSF (GM-CSF) produced through activation of nuclear factor-kappa B (NF- $\mathrm{BB})$, signal transducer and activator of transcription 1 (STAT1) NFAT5, ${ }^{56} 57$ and others; these cells show the an enhanced capacity for antigen presentation and phagocytosis and release many proinflammatory factors, including TNF- $\alpha$, IL-1 $\beta$, IL-12 and IL-18, nitric oxide (NO), IL-12, the intracellular protein NOS2 and suppressor of cytokine signaling 3 (SOCS3), and thus participate in the type I immune response. ${ }^{58}$ Phenotypically, M1 macrophages express high levels of MHC II and CD68, as well as the costimulatory molecules CD80 and CD86 (figure 3) ${ }^{59}$ In liver macrophages, glycogen synthase kinase $3 \beta$ (Gsk3 $\beta$ ) can promote innate proinflammatory immune activation by restraining 


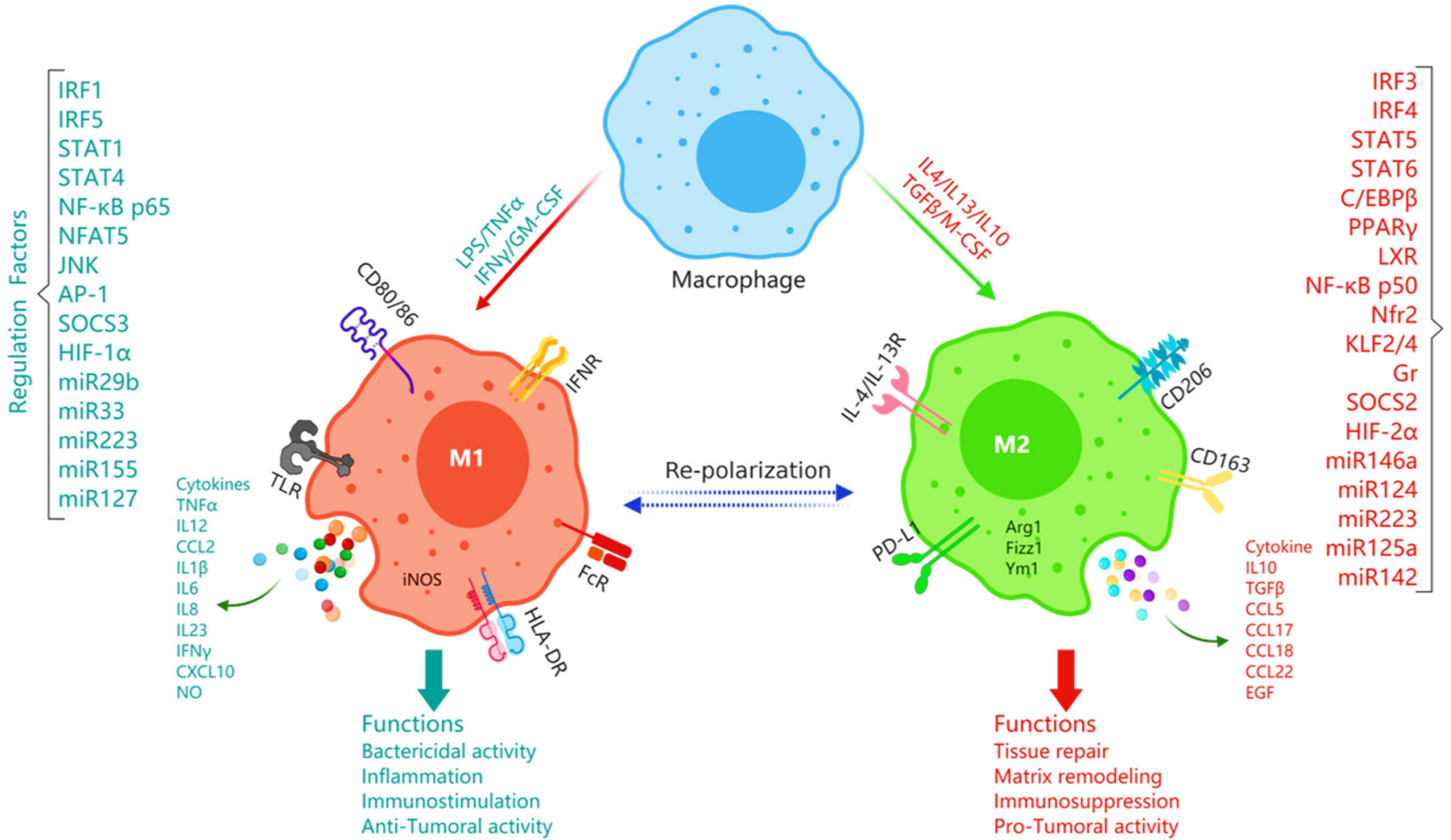

Figure 3 Macrophages can be polarized into M1 and M2 macrophages with different mechanisms. Macrophages can be polarized into two functional categories: classically activated macrophages (M1) and alternatively activated macrophages (M2) under different stimuli through different transcription factors, and show distinct specific markers on the macrophage subsets, which play important roles in pro-inflammation or anti-inflammation. FcR, Fc receptor; GM-CSF, granulocyte-macrophage colony-stimulating factor; IL10, interleukin 10; LPS, lipopolysaccharide; miRNA, microRNA; NF-אB, nuclear factor-kappa B; STAT1, signal transducer and activator of transcription 1 ; TGF- $\beta$, transforming growth factor- $\beta$; TLR, toll-like receptor; TNF $\alpha$, tumor necrosis factor- $\alpha$.

AMPK activation. ${ }^{60}$ M2 macrophages, also known as anti-inflammatory macrophages, are mainly activated by IL-4, IL-13, CSF-1, IL-10, TGF- $\beta$ and helminth infections through activation of STAT6, peroxisome proliferatoractivated receptor $\gamma$ (PPAR $\gamma$ ), SOCS2. (figure 3), and produce many anti-inflammatory factors, including IL-10, TGF- $\beta$ and arginase 1 , participating in the type II immune response, which plays a central role in the response to parasites, tissue remodeling, angiogenesis and allergic diseases. ${ }^{61}$ Phenotypically, M2 macrophages are characterized by the expression of macrophage mannose receptor (CD206) ${ }^{62-64}$ CD163 has also been suggested as an M2 marker, while CD163 is an M2 macrophage marker associated with the transcription factor c-Maf in human tissue; thus, CD163 cannot be recommended as an M2 marker alone. ${ }^{65} \mathrm{c}$-Maf controls many M2-related genes, has direct binding sites within a conservative noncoding sequence of the csf-1r gene and promotes M2-like macrophagemediated $\mathrm{T}$ cell suppression and tumor progression. ${ }^{66}$ Macrophage galactose-type C-type lectin 1 (MGL1) and MGL2 are also expressed in M2 macrophages on stimulation. ${ }^{67}$ Response gene to complement 32 (RGC-32) is a cell cycle regulator expressed in many cells, including macrophages but not monocytes. The absence of RGC-32 does not affect monocyte differentiation to macrophages; however, under M-CSF or IL-4 stimuli, RGC-32 has a relevant role in promoting M2 polarization, and its level of expression still increases M2 macrophages. ${ }^{68}$ In mouse models, some characteristic profiles of M2 macrophages have been reported: MMR (Mrc1), arginase $1(\operatorname{Arg} 1)$, resistin-like molecule $\alpha$ (FIZZ1) and chitinase-like protein Ym 1 were shown to be upregulated, especially in allergic asthma. ${ }^{69}$ Arg1 expression, a hallmark of M2 macrophages, depends on IL-4 and IL-13 and is a direct consequence of STAT6 activation. ${ }^{70}$ The NF-KB p50 subunit, IRF4 and PPAR $\gamma$ have been proposed to enhance the M2 phenotype. ${ }^{71}$ In addition, macrophages exhibit different phenotypic characteristics in different tissues (figure 1).

Tumor-associated macrophages (TAMs), as a specialized phenotype of M2-like macrophages, are phagocytic cells with unclear origins (figure 4), while TAMs originating from circulating $\mathrm{CCR}^{+}$monocytes can alter the TME through endocytic collagen turnover as they are centrally engaged in tumor-associated collagen degradation. ${ }^{72-74}$ Although TAMs share some patterns of M1 and M2 macrophages, these cells have a unique transcriptional profile distinct from M1 or M2 macrophages. Some features of TAMs resemble M2 polarization, such as high production of IL-10 and TGF- $\beta .^{75}{ }^{76}$ In most cases, impaired macrophage accumulation in the TME is associated with control 


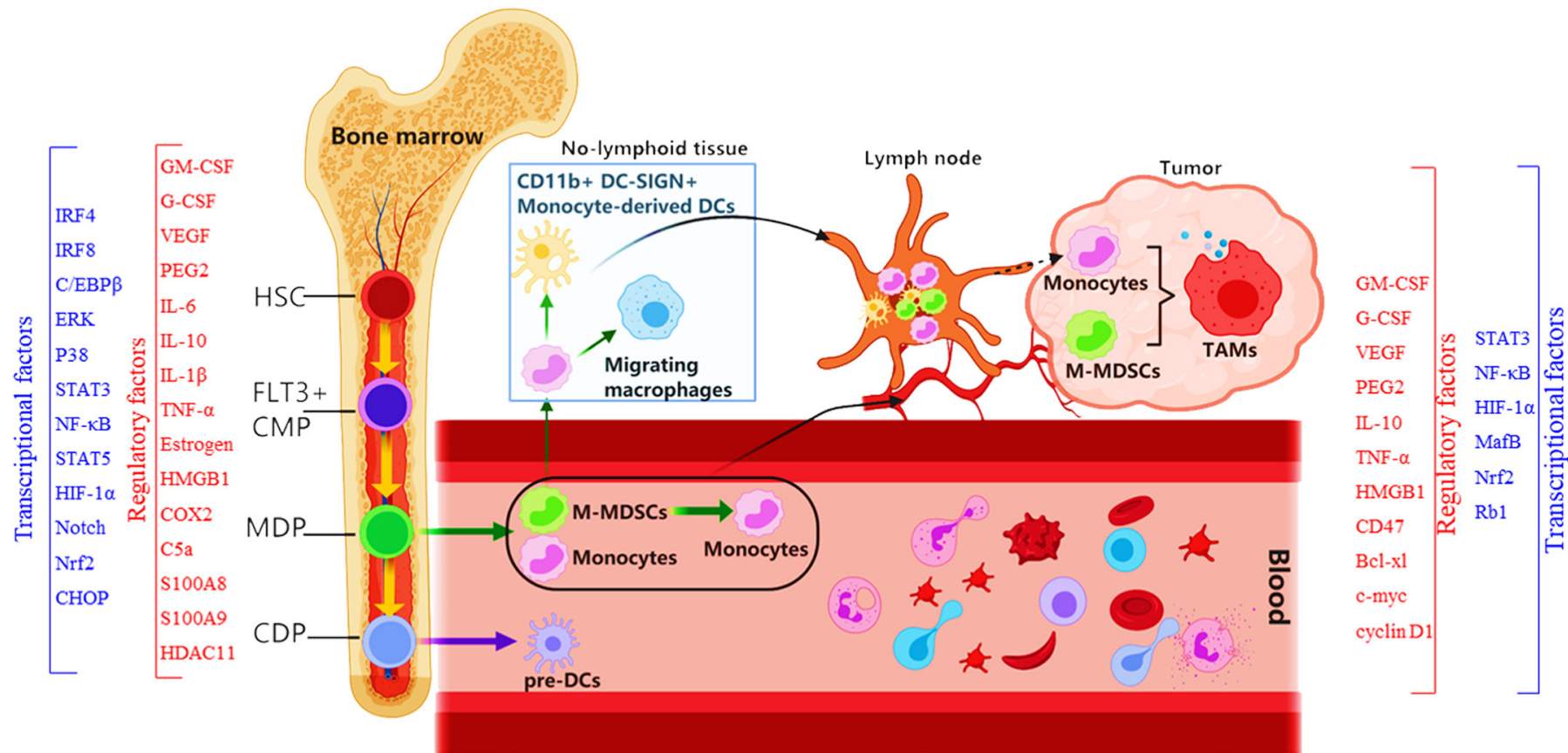

Figure 4 Overview of macrophages involvement in myeloid cell differentiation in cancer through blood circulation. Macrophages development, accumulation, suppressive activity and survival are controlled by a complex network of transcription factors, cytokines and non-cytokine immune regulatory factors. Monocytes and M-MDSCs originate from the common myeloid progenitor (CMP) cell in the bone marrow (also in the spleen of mice) during myelopoiesis (left). They can circulate in the blood and lymph node and home to sites of inflammation and to the solid tumors (right). Under different conditions such as the tumor microenvironment, a variety of factors promote cancer risk, facilitate cancer onset and progression, and polarize TAMs. DCs, dendritic cells; GM-CSF, granulocyte-macrophage colony-stimulating factor; IL-10, interleukin; NF-KB, nuclear factor-kappa B; MDSCs, Myeloid-derived suppressor cells; TAMs, tumor-associated macrophages; TNF $\alpha$, tumor necrosis factor- $\alpha$; VEGF, vascular epidermal growth factor.

of the tumor and reduced metastasis, suggesting a major role of TAMs in cancer. ${ }^{77}$ There is no exact information on how a monocyte precursor can generate TAMs sharing markers of both M1 and M2 macrophages. In regard to this, Movahedi et al reported that the tumor-infiltrating monocyte pool was predominantly $\mathrm{Ly}_{6 \mathrm{C}}^{+} \mathrm{CX} 3 \mathrm{CR} 1^{\text {low }}$ and suggested that Ly6C $\mathrm{C}^{\text {high }}$ monocytes were direct precursors of TAMs. ${ }^{78}$ Then, they subdivided TAMs into two groups according to the expression of MHC II and the suppression of T cell proliferation: (1) MHC II ${ }^{\text {high }}$ TAMs were found to suppress proliferation using an inducible Nitric Oxide Synthase (iNOS)-dependent pathway and (2) MHC II ${ }^{\text {low }}$ TAMs suppressed proliferation via an iNOSindependent pathway. However, according to the origin of the macrophage precursor cells, TAMs can be newly recruited MoD-TAMs, which are mostly generated in a CCR2-dependent manner, and TAMs derived from tissueresident cells (ResTAMs) or embryonic origin TAMs (EmD-ResTAMs), which locally self-maintain without the contribution of adult hematopoiesis and accumulate with tumor expansion in lung tumors. ${ }^{78}$ In mice, the growth of breast tumors induces the accumulation of TAMs, which differ in phenotype and function from mammary tissue macrophages. ${ }^{34} 79$ TAMs express the adhesion molecule Vcam1 and proliferate when they differentiate from inflammatory monocytes but do not transform into the M2 phenotype through the Notch signaling transcription regulator RBPJ. ${ }^{34}{ }^{80}$ It is worth mentioning that Notch mediates the expression of IL-1 $\beta$ and CCL-2 in tumor cells, TAM recruitment and TGF $\beta$-mediated activation of tumor cells by TAMs in basal-like breast cancer. ${ }^{81}$ Thus far, it is not entirely clear how the cascade of events generating TAMs is orchestrated. Resting TAMs are often characterized by high expression of CCL2, CCL5 ${ }^{82}$ and IL-10 and surface markers, including MGL1, MGL2, dectin-1, CD81, MHC II and macrophage scavenger receptor 1, which can facilitate M2-like polarization by enhancing mitochondrial oxidative phosphorylation (OXPHOS) by activating the phosphoinositide 3-kinase (PI3K)/AKT/ GSK3 $\beta / \beta$-catenin pathway. ${ }^{83}$ As previously mentioned, CCR2 depletion plays a driving role in shaping the TME as it leads to largely reduced infiltration of TAMs but strong infiltration of CTLs. In CCR2 $2^{-/}$mice engrafted with colorectal cancer, decreased infiltration of TAMs is associated with reduced tumor burden along with altered extracellular matrix (ECM) composition. It has been described that the TAM activation pathway enhances IRF3 and STAT1 and the release of CCL2, CCL3, CCL5 and IL-10, as well as other molecules, such as PGE2 and VEGF. In murine PDAC models, both inflammatory monocytes and tissue-resident macrophages were identified as sources of TAMs. ${ }^{45}$ Moreover, TAM-released pyrimidines inhibited gemcitabine through molecular competition at the level of drug uptake and metabolism. ${ }^{84}$ Unexpectedly, significant 


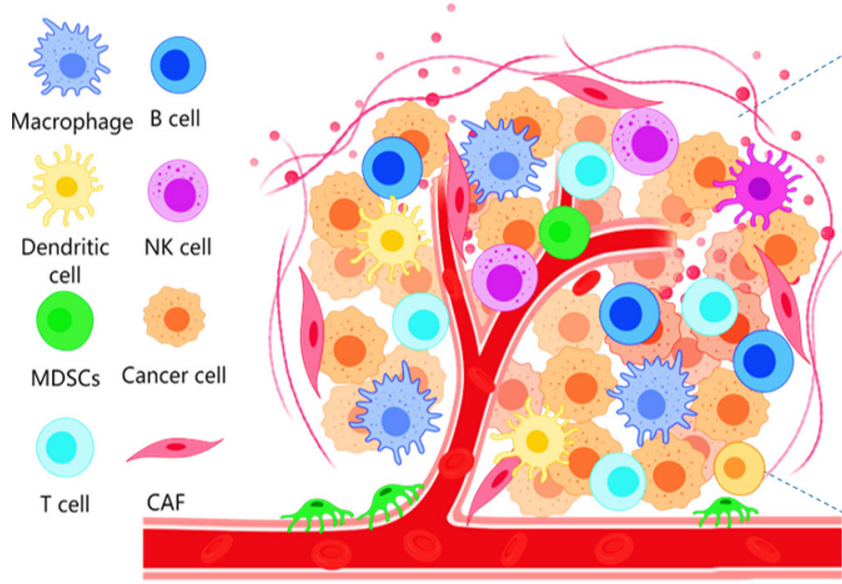

Tumor microenvironment

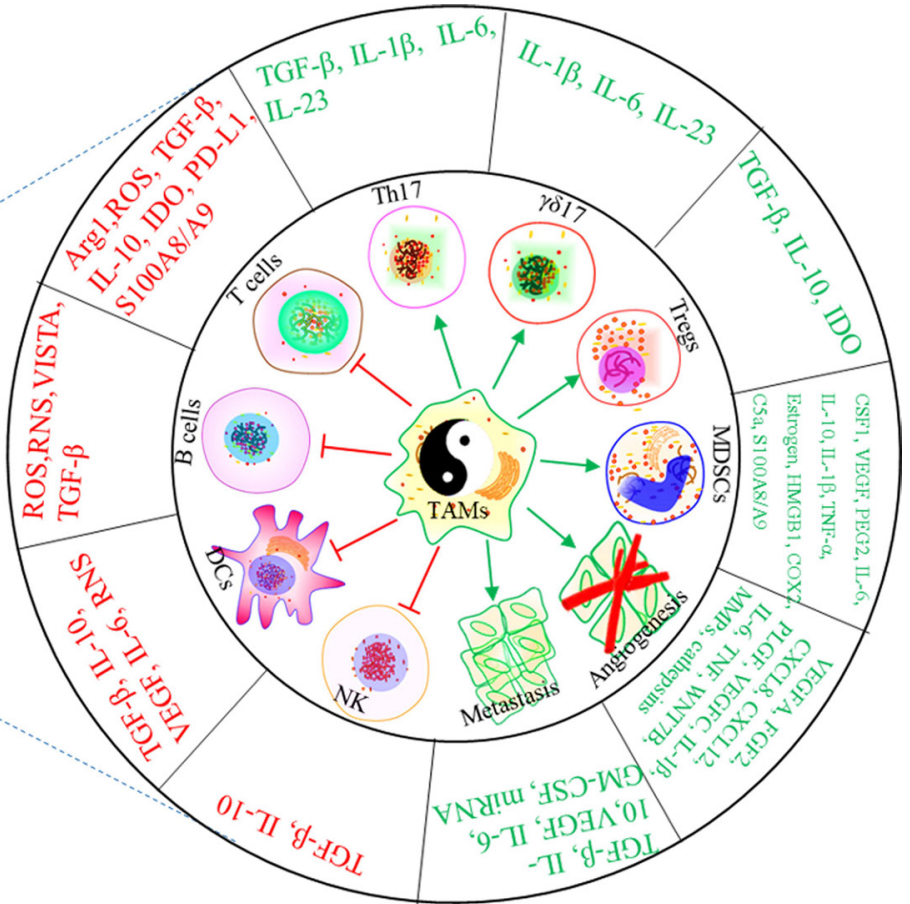

Figure 5 Immunoregulatory effects of TAMs. TAMs in TME can exert the immune regulatory roles on the different immune cells with different mechanisms by producing a variety of cytokines and effector molecules. On the one hands, TAMs inhibit T cell, B cells, NK cells and DCs. On the other hands, TAMs can promote Tregs, Th17 cells, $\gamma \delta \mathrm{T}$ cells and MDSCs, as well as angiogenesis and metastasis of tumor. DCs, dendritic cells; GM-CSF, granulocyte-macrophage colony-stimulating factor; IL10, interleukin; MDSCs, Myeloid-derived suppressor cells; NK, nuclear factor-kappa B; PD-1, programmed cell death protein 1; TAMs, tumor-associated macrophages; TGF $\beta$, transforming growth factor- $\beta$; TME, tumor microenvironment; TNF $\alpha$, tumor necrosis factor- $\alpha$; VEGF, vascular epidermal growth factor.

portions of pancreas-resident macrophages were found to originate from embryonic development and to expand through in situ proliferation during tumor progression. Whereas MoD-TAMs played more potent roles in antigen presentation, EmD-ResTAMs exhibited a profibrotic transcriptional profile, indicative of their role in producing and remodeling molecules in the ECM. ${ }^{45}$ Whether this assumption can be generalized to other models deserves further study, and the generalizability in human tumors is even more hypothetical due to the lack of knowledge of macrophage ontogeny. ${ }^{53}$ TAMs contribute to tumor progression at different levels: by promoting genetic instability, nurturing cancer stem cells, supporting metastasis and taming protective adaptive immunity. ${ }^{85}$ TAMs are critical players in the crosstalk between cancer cells and their microenvironment, contribute to all aspects of tumor progression and are often associated with poor prognosis in cancer patients. ${ }^{86} 87$ These cells have been poorly categorized. However, there is experimental evidence that TAMs appear to share M1 and M2 polarization signatures. In general, TAMs affects tumor progression in the following ways ${ }^{88-90}$ : (1) TAMs can promote the proliferation of tumor cells by producing growth factors, cytokines and chemokines including basic fibroblast growth factor-2, TGF- $\beta$, platelet derived growth factor (PDGF), IL-10, CXCL and VEGF, which not only promotes cell division directly but also indirectly accelerate this process by promoting angiogenesis. (2) TAMs can promote tumor angiogenesis by secreting cytokines, including VEGF, COX-2, and PDGF. In addition, under hypoxia, TAMs upregulate hypoxia-inducible transcription factors and activate expression programs that appear to be proangiogenenic, protumor growth, prometastatic and immunosuppressive. ${ }^{91}$ (3) TAMs is involved in tumor invasion and metastasis by producing several enzymes which can degrade the ECM. Such enzymes include several metalloproteinases (eg, MMP-2, MMP-7, MMP-9 and MMP-12) as well as urokinase-type plasminogen activator that degrade the ECM. Dissolution of the ECM leads to cleavages through which tumor cells can evade and metastasize. ${ }^{79} 92$ (4) TAM mediates immunosuppression, shape and remodel tumor immune microenvironment (TIME), and is involved in tumor immune escape $^{9495}$ (figure 5). In TIME, TAMs inhibits the immune microenvironment and plays an immunosuppressive role by secreting chemokines and cytokines, such as IL-10, TGF- $\beta$ and IDO1, and recruit Tregs to tumor sites, which promote the progression of cancer. ${ }^{76}{ }^{96-98}$ TAMs can also inhibit $\mathrm{T}$ cells by L-arginine depletion through arginase-1 activity, which decreases the expression of the T-cell receptor $\mathrm{CD} 3 \zeta$ chain and impairs T-cell responses. ${ }^{99} 100$ Additionally, TAMs is involved in tumor immune escape, for example, CD24 on the surface of tumor cells interacts with Siglec-10 on the surface of TAMs to promote the immune escape of tumor cells. ${ }^{101-103}$ It is worth noting that chemotherapy will increase the infiltration of TAMs 
into tumor tissues, and the combination of TAM-targeted drugs with chemotherapy can improve the therapeutic effect of chemotherapeutic drugs. ${ }^{104}$

\section{THERAPEUTIC STRATEGIES TARGETING TAMS}

As an important component in the TME, TAMs show high plasticity. ${ }^{105}$ To date, some therapeutic strategies targeting macrophages in animal models and clinical trials have been proposed (all therapeutic strategies targeting TAMs in clinical trials are included in table 1), including reducing or depleting TAMs, repolarizing TAMs toward M1-like macrophages, blocking the inhibitory receptors (immune checkpoints) on TAMs, blocking 'don't eat me' signals, and other potential strategies targeting TAMs (figure 6).

\section{Reducing or depleting TAMs}

\section{CSF1/CSF1R signaling pathway}

Targeting the CSF1/CSF1R signaling pathway is another important effective strategy for treating malignant cancer. Currently, CSF1 is recognized as a classic tumorstimulating factor that recruits macrophages to the tumor site and promotes the polarization of TAMs ${ }^{106}$ Clinically, blocking CSF1R by AMG 820 can significantly reduce the accumulation of immunosuppressive TAMs in solid tumors. ${ }^{107}$ The CSF1R c. $1085 \mathrm{~A}>\mathrm{G}$ genetic variant causes a change of histidine to arginine in the receptor dimerization domain, which confers sensitivity to CSF-1R inhibitors. ${ }^{108}$ Experimentally, BLZ945, a highly selective small molecule CSF-1R inhibitor, can inhibit TAM recruitment in murine breast cancer. In addition, BLZ945 can markedly augment the infiltration of $\mathrm{CD}^{+}$CTLs in cervical cancer and breast cancer and inhibit the growth of neuroblastoma. ${ }^{109}$ RG7155, a CSF1R monoclonal antibody, can inhibit the activation of CSF1R and cause the death of CSF1-dependent macrophages, which can also significantly decrease the intratumoral number of $\mathrm{CSF}_{1} \mathrm{R}^{+}$and $\mathrm{CD} 68^{+} \mathrm{CD} 163^{+}$macrophages, as well as inhibit the growth of several types of cancer. ${ }^{110}$ However, studies in mice and clinical trials in humans have shown that it is insufficient to treat tumors using CSF1/CSF1R blockers alone, and the antitumor efficacy was significantly elevated by treatment with a combination of CSF1/CSF1R blockers and chemotherapy or checkpoint inhibitors. ${ }^{111}$ In murine PDAC, CSF1/CSF1R blockers can enhance the antigen presentation of macrophages and antitumor $\mathrm{T}$ cell responses via inhibition of CSF1R signal transduction; however, programmed cell death protein 1 (PD-1) expressed on these $\mathrm{T}$ cells was obviously upregulated, which weakened the antitumor effect of the CSF1R inhibitor. However, CSF1/CSF1R blockers combined with ICB can strengthen antitumor efficiency. ${ }^{111}$ In tumors, CSF1 expression correlates with the abundance of $\mathrm{CD}^{+} \mathrm{T}$ cells and $\mathrm{CD} 163^{+}$TAMs. Human melanoma cell lines consistently produce CSF 1 after exposure to melanoma-specific $\mathrm{CD}^{+} \mathrm{T}$ cells or $\mathrm{T}$ cell-derived cytokines in vitro, reflecting a broadly conserved mechanism of CSF1 induction by activated $\mathrm{CD}^{+} \mathrm{T}$ cells. ${ }^{112}$ Mining of publicly available transcriptomic datasets suggests co-enrichment of $\mathrm{CD} 8^{+} \mathrm{T}$ cells and CSF1 or various TAM-specific markers in human melanoma, which was associated with nonresponsiveness to PD-1 checkpoint blockade in a small patient cohort. The combination of anti-PD1 and anti-CSF1R antibodies induced the regression of transplanted melanoma in mice, a result that was dependent on the effective elimination of TAMs. ${ }^{112}$ In addition, the use of CSF1R inhibitors to target TAMs is therapeutically appealing but has shown very limited antitumor effects. One limitation to the effect of CSF1R-targeted therapy is that carcinomaassociated fibroblasts (CAFs) are major sources of chemokines that recruit granulocytes to tumors. CSF1 produced by tumor cells caused HDAC2-mediated downregulation of granulocyte-specific chemokine expression by CAFs, which limited the migration of these cells to tumors. ${ }^{113}$ Treatment with CSF1R inhibitors disrupted this crosstalk and triggered a profound increase in granulocyte recruitment to tumors. Combining a CSF1R inhibitor with a CXCR2 antagonist blocked granulocyte infiltration of tumors and showed strong antitumor effects. ${ }^{113114}$

\section{Targeting chemokine}

Targeting chemokines to reduce the infiltration of TAMs into the TME is the main approach used. CCL2 can recruit monocytes expressing CCR2 from peripheral blood to the tumor site, where they further mature into TAMs. ${ }^{115}$ The inactivation of serine-threonine kinase 11 or liver kinase B1 (LKB1) can lead to abnormal production of CCL2, while the loss of LKB1 can increase the expression of CCL2 and thereby elevate the density of macrophages in tumors. Thus, the recruitment and infiltration of macrophages into the TME can be blocked by inhibiting the release of CCL2 from tumor and stromal cells or by using small molecule inhibitors of CCR2. Blockade of the CCL2/CCR2 axis as a therapeutic strategy affecting the recruitment of monocytes/macrophages in HCG suppresses murine liver tumor growth by activating the $\mathrm{T}$ cell antitumor immune response. ${ }^{43}$ Zoledronic acid, a kind of diphosphate compound, can suppress CCL2/ MCP-1 production in tumor cells to reduce the infiltration of TAMs and promote the proliferation of CTLs. However, interruption of CCL2 inhibition exacerbates metastasis and accelerates death because of monocyte release from the bone marrow and enhancement of cancer cell mobilization from the primary tumor, as well as blood vessel formation and increased proliferation of metastatic cells in the lungs in an IL-6- and VEGF-Adependent manner. ${ }^{39}$ In addition to CCL2, it is worth mentioning that CCL5, another C-C motif chemokine ligand, can also recruit TAMs and promote the metastasis and recurrence of tumors, which can be limited by the CCL5 receptor antagonist maraviroc and Raf kinase inhibitor protein. ${ }^{116}$ Macrophage-derived CCL5 facilitates the immune escape of colorectal cancer cells via the NF- $\mathrm{KB}$ p65/STAT3-CSN5-PD-L1 pathway, which is significantly 
Table 1 The combination molecules on TAMs of targeted drugs in clinical trials

\begin{tabular}{|c|c|c|c|}
\hline Targets & Drugs & Cancer type & NCT \\
\hline CSF1 & PD-0360324 & $\begin{array}{l}\text { Recurrent fallopian tube carcinoma } \\
\text { Recurrent ovarian carcinoma } \\
\text { Recurrent primary peritoneal carcinoma }\end{array}$ & NCT02948101 \\
\hline \multirow[t]{22}{*}{ CSF1R } & Edicotinib & $\begin{array}{l}\text { Recurrent adult acute myeloid leukemia } \\
\text { Refractory } \\
\text { Acute myeloid leukemia }\end{array}$ & NCT03557970 \\
\hline & TPX-0022 & $\begin{array}{l}\text { Advanced solid tumor } \\
\text { Metastatic solid tumors }\end{array}$ & NCT03993873 \\
\hline & Cabiralizumab & Peripheral T cell lymphoma & NCT03927105 \\
\hline & & - Tenosynovial giant cell tumor & NCT02471716 \\
\hline & & $\begin{array}{l}\text { Lung cancer } \\
\text { Head and neck cancer } \\
\text { Pancreatic cancer } \\
\text { Ovarian cancer } \\
\text { Renal cell carcinoma } \\
\text { Malignant glioma }\end{array}$ & NCT02526017 \\
\hline & & $\begin{array}{l}\text { Advanced melanoma } \\
\text { Non-small cell lung cancer } \\
\text { Renal cell carcinoma }\end{array}$ & NCT03502330 \\
\hline & & - Peripheral T cell lymphoma & NCT03927105 \\
\hline & IMC-CS4 & - Neoplasms & NCT01346358 \\
\hline & & - Pancreatic cancer & NCT03153410 \\
\hline & & Neoplasms & NCT01346358 \\
\hline & SNDX-6352 & $\begin{array}{l}\text { Solid tumor } \\
\text { Metastatic tumor } \\
\text { Locally advanced malignant neoplasm } \\
\text { Unresectable malignant neoplasm }\end{array}$ & NCT03238027 \\
\hline & & - Metastatic renal cell carcinoma & NCT01265901 \\
\hline & Nilotinib & Malignant solid neoplasms & NCT02029001 \\
\hline & DCC-3014 & $\begin{array}{l}\text { Sarcoma } \\
\text { Advanced sarcoma } \\
\text { High grade sarcoma } \\
\text { Leiomyosarcoma } \\
\text { Undifferentiated pleomorphic sarcoma } \\
\text { Myxofibrosarcoma } \\
\text { Dedifferentiated liposarcoma }\end{array}$ & NCT04242238 \\
\hline & & $\begin{array}{l}\text { Advanced malignant neoplasm } \\
\text { Tenosynovial giant cell tumor, Diffuse }\end{array}$ & NCT03069469 \\
\hline & & $\begin{array}{l}\text { Advanced malignant neoplasm } \\
\text { Tenosynovial giant cell tumor, Diffuse }\end{array}$ & NCT03069469 \\
\hline & PLX73086 & $\begin{array}{l}\text { Solid tumors } \\
\text { Tenosynovial giant cell tumor }\end{array}$ & NCT02673736 \\
\hline & RG7155 & - Solid cancers & NCT02323191 \\
\hline & & Neoplasms & NCT02760797 \\
\hline & & $\begin{array}{l}\text { Fallopian tube adenocarcinoma } \\
\text { Fallopian tube clear cell adenocarcinoma } \\
\text { Fallopian tube endometrioid adenocarcinoma }\end{array}$ & NCT02923739 \\
\hline & & Advanced solid tumors & NCT01494688 \\
\hline & & - Lymphoma, Non-Hodgkin & NCT03369964 \\
\hline
\end{tabular}


Table 1 Continued

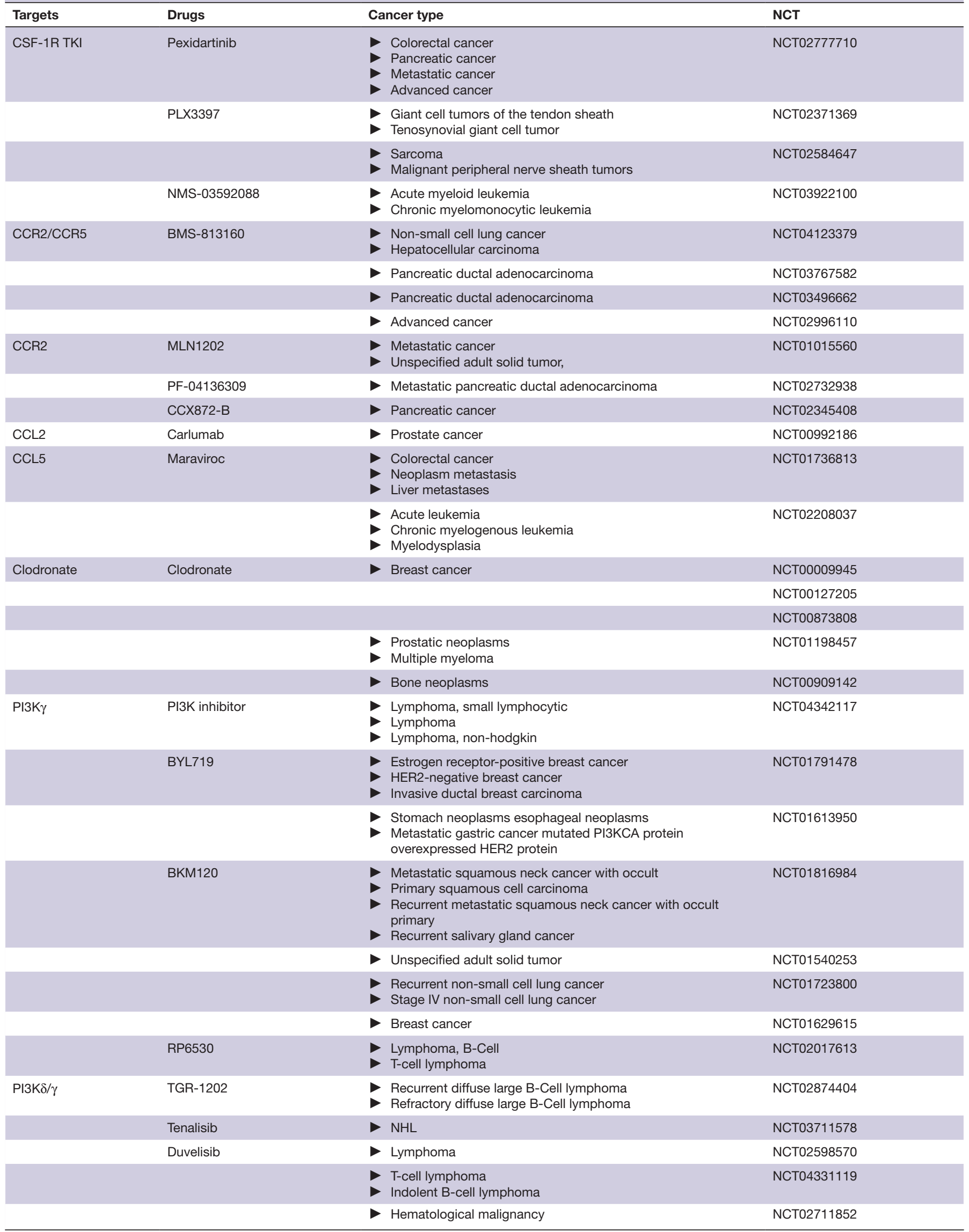


Table 1 Continued

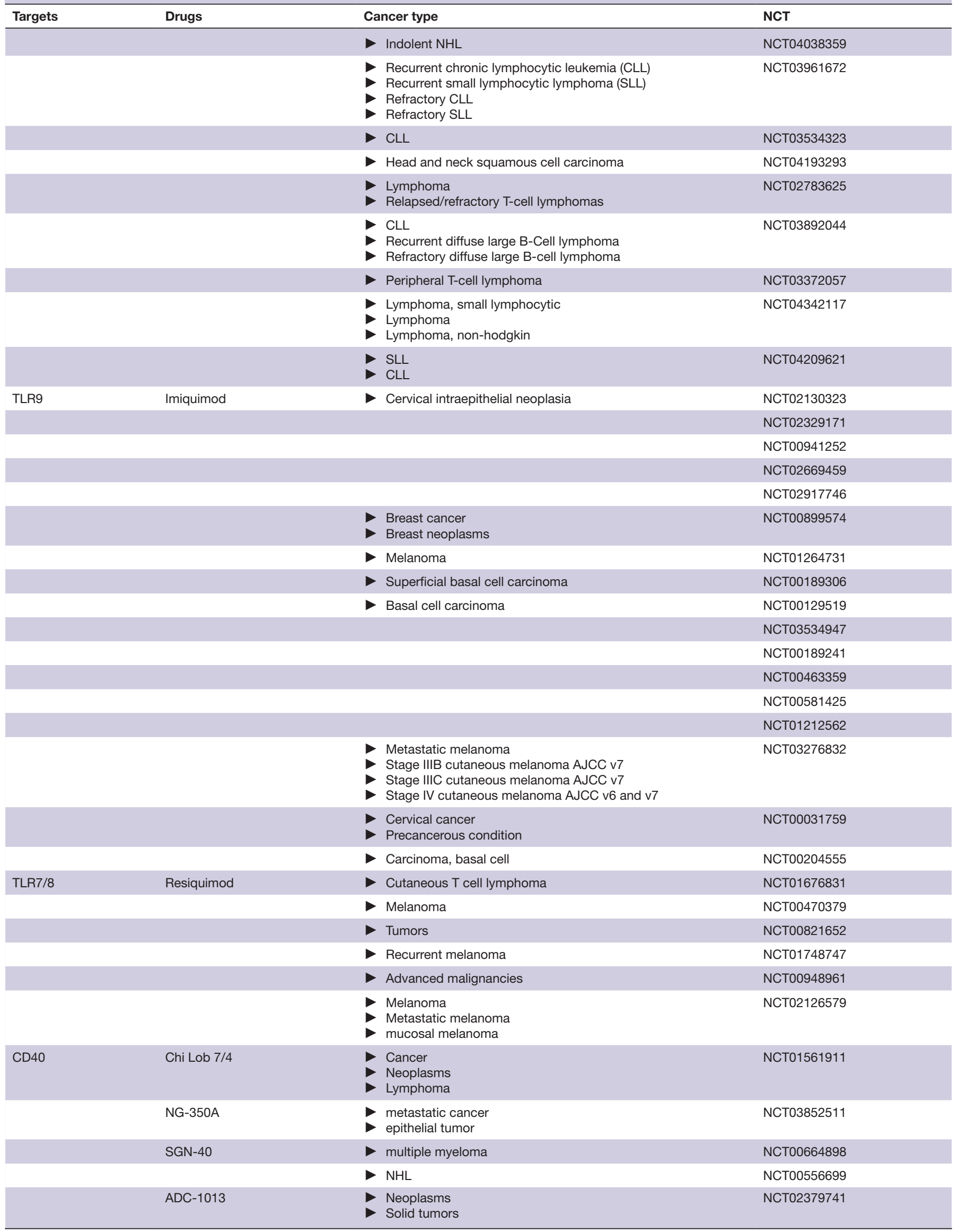


Table 1 Continued

\begin{tabular}{|c|c|c|c|}
\hline Targets & Drugs & Cancer type & NCT \\
\hline & $2141 \mathrm{~V}-11$ & $\begin{array}{l}\text { Cancer } \\
\text { Solid tumor } \\
\text { Cancer of skin }\end{array}$ & NCT04059588 \\
\hline & HCD122 & - Multiple myeloma & NCT00231166 \\
\hline EGFR TKI & Gefitinib & - Non-small cell lung cancer & NCT03157310 \\
\hline \multirow{3}{*}{ Chloroquine } & & - Pancreatic cancer & NCT01777477 \\
\hline & & $\begin{array}{l}\text { Glioblastoma } \\
\text { Astrocytoma, grade IV }\end{array}$ & NCT02432417 \\
\hline & & - Glioblastoma multiforme & NCT00224978 \\
\hline \multirow[t]{15}{*}{ CD47 } & ZL1201 & - Locally advanced solid tumor & NCT04257617 \\
\hline & Hu5F9-G4 & - Acute myeloid leukemia & NCT02678338 \\
\hline & & - Solid tumor & NCT02216409 \\
\hline & & - Acute myeloid leukemia & NCT03248479 \\
\hline & & $\begin{array}{l}\text { Colorectal neoplasms } \\
\text { Solid tumors }\end{array}$ & NCT02953782 \\
\hline & & $\begin{array}{l}\text { NHL } \\
\text { DLBCL } \\
\text { NHL } \\
\text { Diffuse large B cell lymphoma }\end{array}$ & NCT03527147 \\
\hline & & $\begin{array}{l}\text { Lymphoma, non-hodgkin } \\
\text { Lymphoma, large B-cell, diffuse } \\
\text { Indolent lymphoma }\end{array}$ & NCT02953509 \\
\hline & AO-176 & - Solid tumor & NCT03834948 \\
\hline & CC-90002 & - Hematological neoplasms & NCT02367196 \\
\hline & AK117 & - Neoplasms malignant & NCT04349969 \\
\hline & TTI-621 & $\begin{array}{l}\text { Hematological malignancies } \\
\text { Solid tumor }\end{array}$ & NCT02663518 \\
\hline & & $\begin{array}{l}\text { Solid tumors } \\
\text { Melanoma }\end{array}$ & NCT02890368 \\
\hline & & $\begin{array}{l}\text { Lymphoma } \\
\text { Myeloma }\end{array}$ & NCT03530683 \\
\hline & SRF231 & $\begin{array}{l}\text { Advanced solid cancers } \\
\text { Hematological cancers }\end{array}$ & NCT03512340 \\
\hline & ALX148 & $\begin{array}{l}\text { Metastatic cancer } \\
\text { Solid tumor } \\
\text { Advanced cancer } \\
\text { NHL }\end{array}$ & NCT03013218 \\
\hline $\operatorname{SIRP} \alpha$ & Anti-SIRP $\alpha$ & - Hepatocellular carcinoma & NCT02868255 \\
\hline $\mathrm{CD} 47-\operatorname{SIRP} \alpha$ & SRF231 & $\begin{array}{l}\text { Advanced solid cancers } \\
\text { Hematological cancers }\end{array}$ & NCT03512340 \\
\hline
\end{tabular}

CSF1, colony-stimulating factor 1; DLBCL, diffuse large B cell lymphoma; PI3K, phosphoinositide 3-kinase; TAMs, tumor-associated macrophages; TKI, tyrosine kinase inhibitor; TLR, toll-like receptor. 


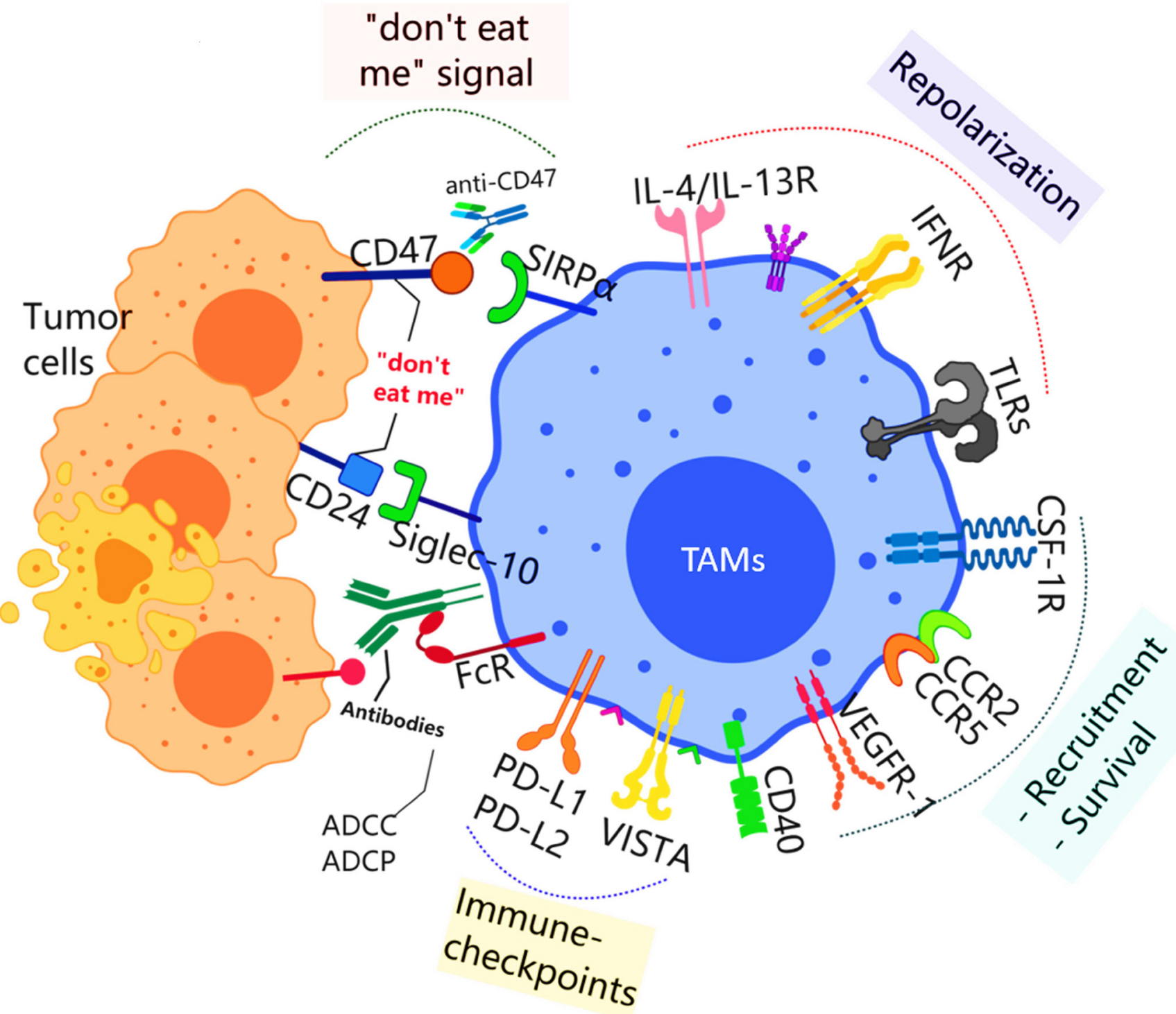

Figure 6 Main therapeutic strategies targeting TAMs. These therapeutic ways are aimed at either activating the anti-tumoral activity, or inhibiting the recruitment, survival and protumoral functions of macrophages. The process of macrophage-mediated antibody-dependent cellular cytotoxicity (ADCC) involves recognition of the therapeutic antibodies by Fc receptors (FcRs) on TAMs. The 'don't eat me' signal including SIRP $\alpha$-CD47 pathway and CD24-Siglec 10 pathway. The antibodies against SIRP $\alpha-$ CD47 pathway and CD24-Siglec 10 pathway can activate macrophage-mediated antibody-dependent cellular phagocytosis (ADCP). Here, the main therapeutic strategies targeting TAMs are generally summarized including the 'don't eat me' signal pathways, repolarization, reducing and decreasing the recruitment and survival, and immune-checkpoints blockades with antibodies. IFNR, interferon receptor; TAMs, tumor-associated macrophages; VEGFR, vascular epidermal growth factor R.

activated by LPS- or HCD-driven macrophage infiltration in an animal model of CRC. ${ }^{117}$

\section{Clodronate}

Clodronate, a chemical agent that induces depletion of macrophages, can significantly deplete TAMs in the TME. ${ }^{118}$ In proof of function experiments, clodronate depleted macrophages in a genetic mouse model of chronic hepatitis and HCC, leading to a significant reduction in $\mathrm{F} 4 / 80^{+}$cells in the livers and spleens of treated mice. ${ }^{119}$ In B16/F10 subcutaneous melanoma, clodronate significantly reduced the size of primary tumors. In tumors, the expression of F4/80 and $\alpha$-SMA was significantly lowered. ${ }^{119}$ In the B16/F10 lung metastatic melanoma model, treatment with clodronate significantly reduced the number of pulmonary nodules. $\mathrm{F} 4 / 80^{+}$cells and microvessel density were also statistically decreased. ${ }^{119}$ Tumor hypoxia and aerobic glycolysis are well-known resistance factors for anticancer therapies. TAMs secrete TNF $\alpha$ to promote tumor cell glycolysis, whereas increased AMPK and PPAR $\gamma$ coactivator $1-\alpha$ in TAMs facilitate tumor hypoxia. Depletion of TAMs by clodronate was sufficient to abrogate aerobic glycolysis and tumor hypoxia, thereby improving the tumor response to anticancer therapies. TAMs depletion led to a significant increase in PD-L1 
expression in aerobic cancer cells as well as $\mathrm{T}$ cell infiltration in tumors, resulting in antitumor efficacy from anti-PD-L1 antibodies, which were otherwise completely ineffective. $^{120}$

\section{REPOLARIZING TAMS TOWARD M1-LIKE MACROPHAGES PI3K $\gamma$ signaling pathway}

Myeloid cell PI3K $\gamma$ plays a role in regulating tumor immune suppression by promoting integrin $\alpha 4$-dependent Myeloid-derived suppressor cell (MDSC) recruitment to tumors and by stimulating the immunosuppressive polarization of MDSCs and TAMs, thereby inhibiting antitumor immunity. On the one hand, PI3K $\gamma$ stimulates the activation of integrin $\alpha 4$ in a manner dependent on BTK, PLC $\gamma$, RAPGEF, Rapla, RIAM, and paxillin. On the other hand, PI3K $\gamma$ can also activate BTK to promote immunosuppressive myeloid cell polarization by inducing the expression of IL-10, TGF- $\beta$, and arginase, which are dependent on mTOR, S6K $\alpha$, and C/EBP $\beta$, and inhibiting the expression of IL-12, IFN- $\gamma$, and Nos2. ${ }^{121}$ Duvelisib (IPI-145), an oral inhibitor of the PI3K $\delta$ and PI3K $\delta$ isoforms, can induce the transformation of TAMs from the immunosuppressive M2-like phenotype to the inflammatory M1-like phenotype. ${ }^{122}$ In PDAC, PI3K $\gamma$ selectively drives immunosuppressive transcriptional programming in macrophages that inhibits adaptive immune responses and promotes tumor cell invasion and desmoplasia. Blockade of PI3K $\gamma$ in PDAC-bearing mice reprogrammes TAMs to stimulate $\mathrm{CD} 8^{+} \mathrm{T}$ cell-mediated tumor suppression and to inhibit tumor cell invasion, metastasis, and desmoplasia. ${ }^{123}$ Additionally, tumor cell-derived C3a modulated TAMs via C3a-C3aR-PI3K $\gamma$ signaling, thereby repressing antitumor immunity. ${ }^{41} \mathrm{PI} 3 \mathrm{~K} \gamma$-deficient macrophages and monocytes produce elevated inflammatory IL-12 and IL-23 in a GSK3 $\alpha / \beta$-dependent manner on toll-like receptor (TLR) stimulation. ${ }^{124}$ Poly(l-glutamic acid)-combretastatin A4 conjugate (PLG-CA4), a novel class of vascular disrupting agents that has notable antitumor activity, induces the polarization of TAMs toward the M2-like phenotype in 4T1 metastatic breast cancer cells. Inhibition of PI3K $\gamma$ attenuates the immunosuppressive effect of PLG-CA4 treatment by decreasing the number of M2-like TAMs. Importantly, PI3K $\gamma$ inhibition synergizes with PLG-CA4 to significantly extend mean survival time. ${ }^{125}$

\section{TLR signaling pathway}

TLRs are important pathogen-recognition receptors expressed by cells of the immune system. Treatment with agonist of TLRs, such as TLR3, TLR4, TLR7/8 and TLR9, is a commonly used procedure that results in rapid activation of innate and adaptive immunity. ${ }^{126}$ The most commonly used TLR agonists are cytosinephosphorothioate guanine oligonucleotides for TLR-9, imiquimod for TLR-7 and poly (I:C) for TLR-3. Stimulation of TLR-3 polarizes macrophages to an M1 phenotype, as evidenced by upregulation of the expression of the costimulatory molecules CD80, CD86, CD40 on macrophages and their enhanced production of cytokines such as IL-6, IL-12 and TNF- $\alpha$; these changes in the macrophages occur via inhibition of the co-inhibitory receptor Tim-3, enhancement of antigen uptake, enhancement of the ability to prime T cells, and inhibition of polarization toward the M2a and M2c subtypes, thus leading to significant increases in M1 macrophages and regression in tumor growth. ${ }^{127}$ Engineered FlaB-secreting bacteria effectively suppressed tumor growth and metastasis in mouse models and prolonged survival, which was associated with TLR5-mediated host reactions in the TME, and these effects were completely abrogated in mice with TLR4 and MyD88 knockout and partly suppressed in TLR5 knockout mice. These results indicate that TLR4 signaling is required for tumor suppression mediated by FlaB-secreting bacteria, whereas TLR 5 signaling augments tumor-suppressive host reactions via induction of the infiltration of abundant immune cells such as monocytes/macrophages and neutrophils via TLR4 signaling. ${ }^{128}$ Tumor-secreted cathepsin K, a vital mediator in the relationship between the intestinal microbiota and CRC metastasis, can bind to TLR4 to stimulate M2 polarization of TAMs via an mTOR-dependent pathway. ${ }^{129}$ Protein S (Pros1), a Mer/Tyro3 ligand produced by tumor cells, can decrease macrophage M1 cytokine expression in vitro and in vivo. Treatment with resiquimod, a TLR7/8 agonist, did not improve survival in mice bearing Pros1-secreting tumors but doubled survival for Pros1deleted tumors, indicating that the combination of Pros1 depletion and TLR7/8 agonists could lead to antitumor responses by way of $\mathrm{M} 1$ polarization. ${ }^{130}$

\section{CD40 and its ligands}

The cell surface molecule CD40, a highly conserved costimulatory protein found on antigen-presenting cells, is a member of the tumor necrosis factor receptor superfamily and is broadly expressed by immune cells, in particular B cells, dendritic cells (DCs), and monocytes, as well as other normal cells and some malignant cells. ${ }^{131}$ AntiCD40 treatment significantly increased the proportion of activated macrophages within the liver, and blockade of macrophage activation using anti-CSF1/1R mAbs abrogated the lethality of anti-CD40/Gem treatment without reducing the antitumor efficacy of the combination treatment in PDAC. Concurrent CSF1R blockade and CD40 agonism led to profound changes in the composition of immune infiltrates, causing an overall decrease in immunosuppressive cells and a shift toward a more inflammatory milieu. Anti-CD40/anti-CSF1R antibody-treated tumors contain fewer TAMs and Foxp $3^{+}$Treg cells, which increases the maturation and differentiation of proinflammatory macrophages and DCs and drives potent priming of effector T cells in draining lymph nodes. ${ }^{132}$ In murine CT26 and MC38 colon adenocarcinoma, the most dramatic changes in the immune infiltrate after antiCD40/anti-CSF1R antibody treatment were observed in macrophage and monocyte populations, which can also 
suppress the growth of melanoma by reducing MMP9 or CCL17/22, which are characteristic of an M2 state, and by simultaneously inducing a polyfunctional inflammatory TAMs subset secreting TNF- $\alpha$, IL- 6 and IL- $12^{133}$; these results were also seen in mesothelioma and colorectal adenocarcinoma. ${ }^{134}$ Consistent with the high CSF1R expression on Ly6 $\mathrm{C}^{\text {low }}$ TAMs, combining anti-CSF1R inhibition and $\mathrm{CD} 40$ agonism resulted in significantly reduced frequencies of MHC II $^{\text {high }}$ and MHC II ${ }^{\text {low }}$ TAMs in tumors. A concomitant increase in MHC $\mathrm{II}^{\text {high }} \mathrm{Ly}^{\mathrm{C}} \mathrm{C}^{\text {int }}$ macrophages suggested that combination therapy reduced the suppressive, tumor-educated TAMs while leaving newly differentiated, pro-inflammatory macrophages to repopulate the TME. The remaining macrophages in the tumors had high expression of the costimulatory molecules CD80 and CD86 and inflammatory cytokines and low levels of MHC II and IL-10R. ${ }^{132}$ In tyrosine kinase inhibition (TKI) of gastrointestinal stromal tumors (GIST), CD40 ligation did not have a direct inhibitory effect on human GIST cells, while the combination of anti-CD40 antibodies and imatinib (a TKI) effectively enhanced therapy directed at TAMs expressing high levels of CD40. ${ }^{135}$

\section{MicroRNA}

MicroRNA (miRNAs) are a large class of small non-coding RNAs that negatively regulate transcript levels through sequence-dependent recognition mechanisms. ${ }^{136}$ Mature miRNAs are processed from hairpin-shaped precursor miRNAs by the RNAse III enzyme double-stranded RNA (dsRNA)-specific endoribonuclease (DICER). ${ }^{137}$ After deletion of DICER in macrophages, M1-like TAM reprogramming is prompted, characterized by hyperactive IFN- $\gamma /$ STAT1 signaling, which abates the immunosuppressive capacity of TAMs and fosters the recruitment of activated CTLs to tumors. CTL-derived IFN- $\gamma$ exacerbates M1 polarization of Dicer1-deficient TAMs and inhibits tumor growth. ${ }^{138}$ Genetic deficiency of miR-21 promotes the polarization of TAMs toward the M1-like phenotype in vivo and in vitro in the presence of tumor cells. By downregulating JAK2 and STAT1, miR-21 inhibits the IFN- $\gamma$-induced STAT1 signaling pathway, which is required for macrophage M1 polarization. ${ }^{139}$ miR-148a expression can reduce the severity of inflammation, decrease NF- $\mathrm{KB}$ and STAT3 activation, and inhibit both spontaneous and carcinogen-induced colon cancer development in mice. miR-148a directly targets several upstream regulators of NF- $\kappa \mathrm{B}$ and STAT3 signaling, including GP130, IKK $\alpha$, IKK $\beta$, IL1R1 and TNFR2, which leads to decreased NF-KB and STAT3 activation in macrophages and colon tissues. ${ }^{140}$ Furthermore, TAMs infiltration is associated with chemoresistance as TAMs secrete IL- 6 and thereby activate the IL-6R/STAT3 pathway; activated STAT3 transcriptionally inhibits the tumor suppressor miR-204-5 p. ${ }^{141}$ Additionally, colon cancer cells harboring the GOF mutated p53 selectively shed miR-1246-enriched exosomes, which can further reprogrammes TAMs into a pro-tumoral state with increases in TGF- $\beta .{ }^{142} \mathrm{M} 2$ macrophage-derived exosomes (MDEs) show high expression levels of miR-21-5 $\mathrm{p}$ and
miR-155-5 p, and MDE-mediated migration and invasion of colon cancer cells depend on these two miRNAs binding to the BRG1 coding sequence and thus downregulating the expression of BRG1, which has been identified as a key factor promoting colon cancer metastasis. ${ }^{143}$ miR-155 can regulate antitumor immune responses by promoting IFN- $\gamma$ production from T cells in the TME. ${ }^{144}{ }^{145}$ In breast cancer, miR-149 downregulation functionally contributes to breast tumor progression by recruiting macrophages to the tumor site and facilitates CSF1 and EGF receptor crosstalk between cancer cells and macrophages. ${ }^{146}$ Hypoxia, the most commonly observed characteristic in cancers, is implicated in the establishment of an immunosuppressive niche. Hypoxic exosomal miR-301a-3p generated by pancreatic cancer cells in a hypoxic microenvironment can polarize M2 macrophages by activating the PTEN/PI3K $\gamma$ signaling pathway. Coculturing pancreatic cancer cells with macrophages in which miR-301a-3p is upregulated or macrophages exposed to hypoxic exosomes enhances their metastatic capacity. ${ }^{147}$ Notably, hypoxic lung cancer-derived extracellular vesicle miR103a can increase the activation of AKT and STAT3 and induce the immunosuppressive and pro-tumoral activity of TAMs by targeting PTEN. ${ }^{148}$ miR-195-5 p is significantly downregulated in CRC tissues and patients with a significantly shortened overall survival. Mechanistically, miR-195-5 p can regulate NOTCH2 expression in a posttranscriptional manner by directly binding to the 3 '-UTR of Notch2 mRNA. Subsequently, miR-195-5 p/NOTCH2 suppresses GATA3-mediated IL-4 production in CRC cells and ultimately prohibits M2-like TAM polarization. ${ }^{149}$

\section{PROMOTING THE PHAGOCYTOSIS AND ANTIGEN PRESENTATION OF TAMS BY BLOCKING 'DON'T EAT ME' SIGNALS CD24-Siglec-10 signaling for cancer immunotherapy}

CD24, also known as heat-stable antigen or small-cell lung carcinoma cluster 4 antigen, is a novel 'don't eat me' signal and a heavily glycosylated glycosylphosphatidylinositolanchored surface protein ${ }^{150151}$ that is known to interact with the inhibitory receptor sialic-acid-binding Ig-like lectin 10 (Siglec-10) on innate immune cells to inhibit inflammatory responses. ${ }^{101} 152153$ In ovarian cancer and breast cancer, CD24 can be the dominant innate immune checkpoint and is a promising target for cancer immunotherapy because of its interaction with Siglec-10, which is highly expressed on TAMs. Genetic ablation and therapeutic blockade of either CD24 or Siglec-10, as well as blockade of the CD24-Siglec-10 interaction using monoclonal antibodies, robustly augment the phagocytosis of macrophages in all CD24-expressing human tumors. ${ }^{103} 154$

\section{The CD47-signal-regulatory protein $\alpha$ axis as an innate immune checkpoint in cancer}

The phagocytic activity of macrophages is regulated by both activating ('eat me') and inhibitory ('don't eat me') signals. ${ }^{155} \mathrm{CD} 47$, a widely expressed transmembrane glycoprotein on cancer cells, serves as a critical 
inhibitory signal, suppressing phagocytosis by binding to signal-regulatory protein alpha (SIRP $\alpha)$ on the surface of macrophages ${ }^{156-159}$; CD47 can be directly regulated by two distinct superenhancers through the TNF-NFKB1 signaling pathway. ${ }^{160}$ Additionally, an exosome-based immune checkpoint blockade strategy (SIRP $\alpha$-exosomes) was developed to antagonize CD $47 .{ }^{161}$ SIRP $\alpha$ is a myeloidspecific immune checkpoint that engages the CD47 'don't eat me' signal on tumors and normal tissues, and this interaction can be blocked by the high-affinity monoclonal antibody KWAR23. Three subsets $\left(\mathrm{CD} 14^{+} \mathrm{SIRP} \alpha^{\text {high }}\right.$, $\mathrm{CD} 14^{-} \mathrm{SIRP}^{\text {low }}$ and $\mathrm{CD} 14^{-} \mathrm{SIRP}^{\text {neg }}$ ) of monocytes/ macrophages based on CD14 and SIRP $\alpha$ expression have been identified. ${ }^{162}$ Following KWAR23 antibody treatment in a human SIRPA knock-in mouse model, macrophages infiltrate human Burkitt's lymphoma xenografts and inhibit tumor growth, generating complete responses in the majority of treated animals. ${ }^{163}$ However, CD47-SIRP $\alpha$ inhibition could potentiate tumor cell phagocytosis, and CD40-mediated activation of a type I IFN response provided a bridge between macrophage-mediated and $\mathrm{T}$ cell-mediated immunity that significantly enhanced durable tumor control and rejection. ${ }^{164}$ MHC I can control the phagocytic function of macrophages. Expression of the common MHC I component $\beta 2$-microglobulin by cancer cells directly protects them from phagocytosis, which is mediated by the inhibitory receptor LILRB1, whose expression is upregulated on the surface of macrophages, including TAMs. Disruption of either MHC I or LILRB1 potentiated phagocytosis of tumor cells both in vitro and in vivo, suggesting that the MHC I-LILRB1 signaling axis is an important regulator of the effector function of innate immune cells. ${ }^{165}$ Recently, responsive exosome nanobioconjugates were synthesized for cancer therapy. Azide-modified exosomes derived from M1 macrophages were conjugated with dibenzocyclooctynemodified antibodies against CD47 and SIRP $\alpha$ through pH-sensitive linkers. In the acidic TME, the benzoicimine bonds of the nanobioconjugates are cleaved to release aSIRP $\alpha$ and aCD47, which can block SIRP $\alpha$ on macrophages and CD47, respectively, leading to abolished 'do not eat me' signaling and improved phagocytosis by macrophages. In addition, native M1 exosomes effectively reprogramme macrophages from the protumoral M2 to the antitumoral M1 phenotype. ${ }^{166}$ Notably, the CD47-SIRP $\alpha$ interaction requires Fc-Fc $\gamma \mathrm{R}$ interactions to maximize the antitumor efficacy of macrophages in $\mathrm{T}$ cell lymphomas. ${ }^{167}$ Glutaminyl-peptide cyclotransferaselike protein (QPCTL) was identified as a major component of the CD47-SIRP $\alpha$ checkpoint. Interference with QPCTL activity enhances antibody-dependent cellular phagocytosis and cellular cytotoxicity against tumor cells. ${ }^{168}$ Acute myeloid leukemia (AML) is organized as a cellular hierarchy initiated and maintained by a subset of self-renewing leukemia stem cells (LSCs). CD47 is more highly expressed on AML LSCs than on their normal counterparts, and increased CD47 expression predicted worse overall survival in three independent cohorts of adult AML patients. Furthermore, blocking CD47 with the monoclonal antibody TTI-621 preferentially enabled phagocytosis of AML LSCs and inhibited their engraftment in vivo. Finally, treatment of human AML LSCengrafted mice with an anti-CD47 antibody targeted and depleted AML LSCs. ${ }^{169} 170$ Moreover, macrophage phagocytosis activated by anti-CD47 antibodies primed CD $8^{+} \mathrm{T}$ cells to exhibit cytotoxic functions in vivo. ${ }^{171}$ Additionally, targeting the IRF7-SAPK/JNK pathway to induce M1 characteristics in TAMs contributed to prolonged survival in leukaemic mice. ${ }^{172}$ In bladder cancer, CD47 is highly expressed by bladder tumor-initiating cells compared with the rest of the tumor. ${ }^{173}$ Blockade of CD47 by a mAb resulted in macrophage engulfment of bladder cancer cells ${ }^{174}$ and acute lymphoblastic leukemia in vitro, ${ }^{175}$ and the combination of the monoclonal anti-CD20 antibody rituximab with an anti-CD47 antibody eradicated human B cell non-Hodgkin's lymphoma (NHL) through a mechanism involving combined Fc receptor (FcR)-dependent and FcR-independent stimulation of phagocytosis. ${ }^{176} \mathrm{In}$ canine diffuse large B cell lymphoma in a murine xenograft model, augmented responses are observed when CD47-blocking therapies are combined with 1E4-cIgGB, a canine-specific antibody against CD20, resulting in synergy in vitro and in vivo and eliciting cures in $100 \%$ of subjects. ${ }^{177}$ In pediatric malignant primary brain tumors, a humanized anti-CD47 antibody, Hu5F9-G4, has demonstrated therapeutic efficacy in vitro and in vivo in patient-derived orthotopic xenograft models. ${ }^{178}$ Hu5F9-G4 combined with rituximab has also shown promising activity in patients with aggressive and indolent lymphoma. No clinically significant safety events were observed in the initial study. ${ }^{179}{ }^{180}$ Calreticulin is a prophagocytic signal highly expressed on the surface of several human cancers, including AML and lymphoblastic leukaemias, chronic myeloid leukemia, NHL, bladder cancer, GBM, ${ }^{181}$ small lung cancer and ovarian cancer, but minimally expressed on most normal cells. ${ }^{157}$ Increased CD47 expression correlated with high calreticulin levels in cancer cells and was necessary for protection from calreticulin-mediated phagocytosis. Phagocytosis induced by anti-CD47 antibodies requires the interaction of target cell calreticulin with its receptor low-density lipoprotein-receptor related protein (LRP) on phagocytic cells, as blockade of the calreticulin/LRP interaction prevents anti-CD47 antibody-mediated phagocytosis. Last, increased calreticulin expression is an adverse prognostic factor in diverse tumors, including neuroblastoma, bladder cancer and NHL. ${ }^{157} 182183$

\section{Other potential molecular targets}

Some drugs and molecular targets can also affect the polarization of TAMs. M2 macrophages show higher insulin-like growth factor-1 (IGF-1) and CD163 expression than M1 macrophages and increase hepatoma growth. Sorafenib can reduce the release of CD163 and IGF-1 by M2 macrophages and slow the proliferation of $\mathrm{HuH} 7$ and HepG2 cells driven by M2 macrophages. 
IGF-receptor blockade with NVP-AEW541 can decelerate growth by M2 macrophage-conditioned culture media in a dose-dependent manner. A transient mCD163 (CD163 mRNA) reduction during sorafenib treatment indicated coherent M2 macrophage inhibition in patients with HCC. ${ }^{184}$ Notably, sorafenib induces pyroptosis in macrophages and triggers NK-mediated cytotoxicity against HCC. ${ }^{185}$ Moreover, blocking IGF in combination with paclitaxel, a chemotherapeutic agent commonly used to treat breast cancer, showed a significant reduction in tumor cell proliferation and lung metastasis in preclinical breast cancer models compared with paclitaxel monotherapy. ${ }^{186}$ Additionally, IGF-2 can commit preprogrammed mature macrophages to OXPHOS, such that maturing macrophages can be cultured to become anti-inflammatory cells. ${ }^{187}$ Polyinosinic-polycytidylic acid, a synthetic molecule similar to ddsRNA that potentially inhibits liver tumors, can also reprogramme TAMs toward an M1-like phenotype ${ }^{188}$ Gefitinib, an EGFR TKI used to treat non-small-cell lung cancer (NSCLC), can significantly inhibit IL-13-induced M2-like polarization and decrease the expression of CD206, CD163 and other specific M2 marker genes (Mrc1, Ym1, Fizz1, Arg1, IL-10 and CCL2) ${ }^{189}$ In Lewis lung cancer, a small concentration of gefitinib significantly inhibited IL-13-induced M2-like polarization of macrophages. In RAW 264.7 cells, gefitinib inhibits IL-13-induced phosphorylation of STAT6, which was a crucial signaling pathway in macrophage M2-like polarization. In LLC mice metastasis model, oral administration of gefitinib significantly reduced the number of lung metastasis nodules, down-regulated the expression of M2 marker genes and the percentages $\mathrm{CD} 206^{+}$and $\mathrm{CD} 8^{+}$macrophages in tumor tissues. ${ }^{190}$ Neferine, an antiangiogenesis reagent, is one of the most promising agents for the treatment of high-grade serous ovarian carcinoma (HGSOC) and can induce autophagy through mTOR/p70S6K pathway inhibition and suppress M2 macrophage polarization. ${ }^{191}$ Bone morphogenetic protein (BMP)-dependent signals originate from stromal bladder tissue and mediate urothelial homeostasis. The expression of BMP4 is related to monocyte/macrophage polarization toward the M2 phenotype. ${ }^{192}$ The inhibition of TAM infiltration can also reduce the number of TAMs. Metformin is capable of repressing prostate cancer progression by inhibiting infiltration of TAMs via inhibition of the COX2/PGE2 axis. ${ }^{193}$ Dioscin, an herbal steroidal saponin, improves the secretion of proinflammatory cytokines (IL- 6 , TNF- $\alpha$ and IL- $1 \beta$ ) and the phagocytic capacity of TAMs by increasing M1 phenotype polarization. ${ }^{194}$ Notably, leucine-rich repeat-containing $\mathrm{G}$ protein-coupled receptor 4 (Lgr4; also known as Gpr48) promotes macrophage M2 polarization through Rspo/Lgr4/Erk/Stat3 signaling. Importantly, blockade of Rspo-Lgr4 signaling can overcome LLC resistance to anti-PD-1 therapy and improve the efficacy of PD-1targeted immunotherapy in B16F10 melanoma. ${ }^{195}$ CSCs contribute to the progression and androgen deprivation therapy (ADT) resistance of prostate cancer and promote the transformation of monocytes/macrophages into TAMs, and CSC-educated TAMs reciprocally promote the stem-like properties of CSCs, progression and ADT resistance through IL-6/STAT3 ${ }^{196}$; these effects are also seen in NSCLC. ${ }^{197}$ In human solid tumors harboring excessive STAT3 activity, hematopoietic cell kinase can suppress M2 macrophage polarization by inhibiting STAT3. ${ }^{198}$ Additionally, inhibition of STAT3-induced gene expression can reprogramme macrophages toward an antitumor state by blocking ERK5. ${ }^{199}$ Chloroquine, a lysosomotropic agent that is used to treat malaria, plays an important role in antitumor therapy by redirecting TAMs toward the M1 phenotype, which increases macrophage lysosomal $\mathrm{pH}$, causing $\mathrm{Ca}^{2+}$ release via the lysosomal $\mathrm{Ca}^{2+}$ channel mucolipin-1 (Mcoln1), and further induces the activation of p38 and NF-кB. ${ }^{200}$ The EMT inducer SNAIL1 regulates breast cancer metastasis, and its expression in human primary breast tumors predicts poor outcomes. The SNAIL1-dependent tumor cell secretome modulates primary TAMs polarization by regulating the production of GM-CSF, IL- $1 \alpha$, IL- 6 and TNF- $\alpha$ by breast cancer cells. ${ }^{201}$ In KRAS-mutant lung adenocarcinoma (LUAD), loss of the histone chaperone Asfla in tumor cells sensitizes tumors to anti-PD-1 treatment, revealing that tumor cell-intrinsic Asfla deficiency induces the polarization of M1-like macrophages by upregulating GM-CSF expression and potentiates $\mathrm{T}$ cell activation in combination with anti-PD-1 antibodies. ${ }^{202}$ The p38/MAPKAP kinase 2 (MK2) axis controls the synthesis of proinflammatory cytokines that mediate both chronic inflammation and tumor progression. Blockade of this pathway can suppress inflammation and prevent colorectal tumorigenesis in a mouse model of inflammation-driven colon cancer because MK2 promotes polarization of TAMs toward protumorigenic, proangiogenic M2-like macrophages. ${ }^{203}$ In the TME, hedgehog $(\mathrm{Hh})$ signaling in myeloid cells is critical for M2 TAMs polarization and tumor growth. Furthermore, Hh-induced functional polarization of TAMs suppresses CD8 ${ }^{+} \mathrm{T}$ cell recruitment to the TME through the inhibition of CXCL9 and CXCL10 production by TAMs. ${ }^{204}$ Furthermore, TAMs exhibit antitumoral properties in sonic Hh-related medulloblastoma. ${ }^{205}$

\section{Radiotherapy and TAMs}

Radiotherapy (RT), besides tumor cells, also affects the TME. RT-induced inflammatory response contains five phases: innate recognition, initiation of inflammation, antigen presentation, effector response and resolution. Macrophages play an important role in all phases. RT can cause the accumulation of radioresistant M2-like TAMs. ${ }^{206}$ Furthermore, an abscopal effect is observed. The abscopal effect is phenomenon in which local RT is associated with the regression of metastatic cancer at a distance from the irradiated site..$^{207-209}$ The abscopal effect is an immune response, which can also be mediated by macrophages, activated by inflammatory agents (cytokines, DAMPs, ROS/RNS) originating from irradiated TME. In addition, RT can also induce the transcription of 
HIF-1 $\alpha$, which leads to increased expression of CXCL12, CCL2, CSF1 and VEGF, which recruit macrophages and promote their immunosuppressive function. ${ }^{210}$ HIF-1 $\alpha$ and IFN- $\gamma$ signaling also induces the expression of PD-L1 in TAMs and tumor cells, which suppresses the antitumor immune response. ${ }^{211} 212$ Moreover, RT causes cancer cell death partially via apoptosis which is known to induce immunosuppressive and anti-inflammatory response in macrophages. Apoptotic cells drive differentiation of macrophages into the M2 phenotype with enhanced secretion of anti-inflammatory cytokines such as TGF- $\beta$ and IL-10 and upregulation of Arg1 $1{ }^{213}$ It's important to note that RT can recruit both M1 and M2 macrophages from bone marrow-derived myeloid cells. ${ }^{213}$ The balance of M1 vs M2 macrophages induced by RT may depend on the radiation dose. For example, both single-dose ( $25 \mathrm{~Gy}$ ) and fractionated irradiation $(15 \times 4 \mathrm{~Gy})$ resulted in intratumoral macrophages with both higher expression of both M1 markers including COX2 and iNOS as well as M2 markers including Arg1 in a murine prostate cancer model. ${ }^{211}$ In PDAC, low-dose $\gamma$ irradiation led to the differentiation of iNOS + M1 macrophages, which promoted efficient recruitment of tumor-specific T-cells by helping normalize the tumor vasculature. ${ }^{210}$ Low doses $(<2 \mathrm{~Gy})$ may also activate immunosuppression and angiogenesis. In mice, after a low dose of radiation, M2 macrophages suppress the antitumor response and promote metastasis through the production of Arg1 and TGF- $\beta$ and IL-10. In addition, high doses of RT ( $>8 \mathrm{~Gy}$ ) may promote the antiinflammatory activation of macrophages, ${ }^{214}$ and a dose of $20 \mathrm{~Gy}$ activates the M2 TAM with tolerogenic properties by inducing COX-2/PGE2 and NO. ${ }^{212}$

\section{CONCLUSIONS AND FUTURE PERSPECTIVES}

Although significant advances have been made in targeting TAMs to treat tumors, some risks and limitations remain. For example, in murine mammary tumors, CCR2-expressing inflammatory monocytes can be recruited to the primary tumors and metastatic sites, and CCL2 neutralization inhibits metastasis by retaining monocytes in the bone marrow. Blocking CCL2 inhibition leads to increased metastasis and accelerated death. This is due to the release of monocytes in the bone marrow and increased mobilization of cancer cells in the primary tumor, as well as the proliferation of metastatic cells and blood vessel formation in the lung. Targeting TAMs by inhibiting CSF1R has been reported to reduce tumor growth and metastasis, and such therapies are currently in clinical trials. Application of neutralizing anti-CSF1R and anti-CSF 1 antibodies, or treatment with two different small molecule inhibitors of CSF1R, can actually increase spontaneous metastasis without altering primary tumor growth in mice with two independently derived breast tumors. Blocking CSF1R or CSF1 can lead to elevated serum G-CSF levels, an increased frequency of pulmonary neutrophils associated with primary tumors and metastases, and an increased number of neutrophils and
Ly6 $\mathrm{C}^{\text {high }}$ monocytes in peripheral blood. Macrophages are a key factor in the complex interaction between the immune system and tumors and play an important role in promoting tumor growth and vascular system formation and in disrupting the balance of the TME, suggesting that they are an important target for tumor prevention and treatment. TAMs in the tumor are encouraged by the tumor to undergo M2-like polarization, which promotes the growth of the tumor and seriously affects prognosis. Therefore, the development and application of drug delivery systems targeting TAMs and the TME are of great significance. Immunosuppressive agents and some natural drugs inhibit the expression of TAMs; nanoparticle drugs, phosphoric acid compounds, and some natural medicines convert TAMs from the M2 to the M1 phenotype. The replacement of TAMs with CTLs will become a new therapeutic direction for patients with advanced tumors. Targeting of CCL2 and CSF1R may have some risks, which can be eliminated with combination strategies. As mentioned above, the infiltration of TAMs in TME is associated with poor prognosis. However, instead of removing TAMs, it is better to transform TAMs into antitumor effectors, which may be the most promising strategy related to TAMs used to treat tumors in the future. Besides, at present, high dose of RT is often used in clinical. However, high dose may promote the antiinflammatory activation of macrophages, and further suppress antitumor immunity. Therefore, combining rRT with a reprogramming strategy targeting TAMs may amplify the antitumor efficiency compared with a single treatment strategy.

Acknowledgements We thank the Postdoctoral Foundation of Peking-Tsinghua Center for Life Sciences (CLS) to Dr Chunxiao Li.

Contributors Dr. Chunxiao Li conceived, wrote, revised the manuscript, drew all figures, and supported the foundations; Xiaofei Xu and Shuhua Wei contributed equally to collect materials. Lixiang Xue gave us some advices. Ping Jiang collected parts of materials and gave suggestion on radiotherapy. Junjie Wang conceived the structure of manuscript.

Funding This work was supported by the National Natural Science Foundation of China (81803051 to Dr. Chunxiao Li), the Natural Science Foundation of Beijing Municipality (7192220 to Dr. Chunxiao Li), the China Postdoctoral Science Foundation (2018T110015 to Dr. Chunxiao Li) and the China Postdoctoral Science Foundation (2017M620545 to Dr. Chunxiao Li).

Competing interests None declared.

Patient consent for publication Not required.

Provenance and peer review Not commissioned; externally peer reviewed.

Open access This is an open access article distributed in accordance with the Creative Commons Attribution Non Commercial (CC BY-NC 4.0) license, which permits others to distribute, remix, adapt, build upon this work noncommercially, and license their derivative works on different terms, provided the original work is properly cited, appropriate credit is given, any changes made indicated, and the use is non-commercial. See http://creativecommons.org/ licenses/by-nc/4.0/.

Author note Dr. Chunxiao Li is leading correspondence for acedemic communication; Prof. Junjie Wang is senior correspondence

ORCID iD

Chunxiao Li http://orcid.org/0000-0002-1805-140X 


\section{REFERENCES}

1 Lemke G. How macrophages deal with death. Nat Rev Immunol 2019;19:539-49.

2 Murray PJ, Allen JE, Biswas SK, et al. Macrophage activation and polarization: Nomenclature and experimental guidelines. Immunity 2014:41:14-20.

3 Metchnikoff E. Untersuchungen über die mesodermalen Phagocyten einiger Wirbeltiere. Biologisches centralblat 1883;3:560-5.

4 Metchnikoff E. Immunity in the infectious diseases. New York: Macmillan, 1905

5 Varga T, Czimmerer Z, Nagy L. Ppars are a unique set of fatty acid regulated transcription factors controlling both lipid metabolism and inflammation. Biochim Biophys Acta 2011;1812:1007-22.

6 Gordon S. Phagocytosis: an immunobiologic process. Immunity 2016;44:463-75.

7 Ebert RH, Florey HW. The extravascular development of the monocyte observed in vivo. Br J Exp Pathol 1939;20:342-56.

8 Virolainen M. Hematopoietic origin of macrophages as studied by chromosome markers in mice. J Exp Med 1968;127:943-52.

9 van Furth R, Cohn ZA, Hirsch JG, et al. The mononuclear phagocyte system: a new classification of macrophages, monocytes, and their precursor cells. Bull World Health Organ 1972;46:845-52.

10 North RJ, Mackaness GB. Immunological control of macrophage proliferation in vivo. Infect Immun 1973;8:68-73.

11 Rosenstreich DL, Oppenheim JJ. The role of macrophages in the activation of T and B lymphocytes in vitro. In: Immunobiology of the macrophage, 1976: 161-99.

12 Nathan CF, Murray HW, Wiebe ME, et al. Identification of interferongamma as the lymphokine that activates human macrophage oxidative metabolism and antimicrobial activity. $J$ Exp Med 1983;158:670-89.

13 Mosmann TR, Coffman RL. Th1 and Th2 cells: different patterns of lymphokine secretion lead to different functional properties. Annu Rev Immunol 1989;7:145-73.

14 Abramson SL, Gallin Jl. II-4 inhibits superoxide production by human mononuclear phagocytes. J Immunol 1990;144:625-30.

15 Stein M, Keshav S, Harris N, et al. Interleukin 4 potently enhances murine macrophage mannose receptor activity: a marker of alternative immunologic macrophage activation. J Exp Med 1992;176:287-92.

16 Mosser DM, Edwards JP. Exploring the full spectrum of macrophage activation. Nat Rev Immunol 2008;8:958-69.

17 Biswas SK, Mantovani A. Macrophage plasticity and interaction with lymphocyte subsets: cancer as a paradigm. Nat Immunol 2010;11:889-96.

18 DeNardo DG, Ruffell B. Macrophages as regulators of tumour immunity and immunotherapy. Nat Rev Immunol 2019;19:369-82.

19 Li F, Okreglicka KM, Pohlmeier LM, et al. Fetal monocytes possess increased metabolic capacity and replace primitive macrophages in tissue macrophage development. Embo J 2020;39:e103205.

20 Blériot C, Ng LG, Ginhoux F. "Cloaking" on time: a cover-up act by resident tissue macrophages. Cell 2019;177:514-6.

21 Locati M, Curtale G, Mantovani A. Diversity, mechanisms, and significance of macrophage plasticity. Annu Rev Pathol 2020;15:123-47.

22 Heidt T, Courties G, Dutta P, et al. Differential contribution of monocytes to heart macrophages in steady-state and after myocardial infarction. Circ Res 2014;115:284-95.

23 Dutta P, Nahrendorf M. Monocytes in myocardial infarction. Arterioscler Thromb Vasc Biol 2015;35:1066-70.

24 Arfvidsson J, Ahlin F, Vargas KG, et al. Monocyte subsets in myocardial infarction: a review. Int $J$ Cardiol 2017;231:47-53.

25 Peet C, Ivetic A, Bromage DI, et al. Cardiac monocytes and macrophages after myocardial infarction. Cardiovasc Res 2020;116:1101-12.

26 Dewald O, Zymek P, Winkelmann K, et al. CCL2/Monocyte chemoattractant protein-1 regulates inflammatory responses critical to healing myocardial infarcts. Circ Res 2005;96:881-9.

27 Nahrendorf M, Swirski FK, Aikawa E, et al. The healing myocardium sequentially mobilizes two monocyte subsets with divergent and complementary functions. J Exp Med 2007;204:3037-47.

28 Jung K, Kim P, Leuschner F, et al. Endoscopic time-lapse imaging of immune cells in infarcted mouse hearts. Circ Res 2013;112:891-9.

29 Hilgendorf I, Gerhardt LMS, Tan TC, et al. Ly-6Chigh monocytes depend on $\mathrm{Nr} 4 \mathrm{a} 1$ to balance both inflammatory and reparative phases in the infarcted myocardium. Circ Res 2014;114:1611-22.

30 Murray PJ. On macrophage diversity and inflammatory metabolic timers. Nat Rev Immunol 2020;20:89-90.

31 Epelman S, Lavine KJ, Randolph GJ. Origin and functions of tissue macrophages. Immunity 2014;41:21-35.
32 Sheng J, Ruedl C, Karjalainen K. Most tissue-resident macrophages except microglia are derived from fetal hematopoietic stem cells. Immunity 2015;43:382-93.

33 Shemer A, Jung S. Differential roles of resident microglia and infiltrating monocytes in murine CNS autoimmunity. Semin Immunopathol 2015;37:613-23.

34 Franklin RA, Liao W, Sarkar A, et al. The cellular and molecular origin of tumor-associated macrophages. Science 2014;344:921-5.

35 Shand FHW, Ueha S, Otsuji M, et al. Tracking of intertissue migration reveals the origins of tumor-infiltrating monocytes. Proc Natl Acad Sci U S A 2014;111:7771-6.

36 Noy R, Pollard JW. Tumor-associated macrophages: from mechanisms to therapy. Immunity 2014;41:49-61.

37 Tymoszuk P, Evens H, Marzola V, et al. In situ proliferation contributes to accumulation of tumor-associated macrophages in spontaneous mammary tumors. Eur J Immunol 2014;44:2247-62.

38 Pathria P, Louis TL, Varner JA. Targeting tumor-associated macrophages in cancer. Trends Immunol 2019;40:310-27.

39 Bonapace L, Coissieux M-M, Wyckoff J, et al. Cessation of CCL2 inhibition accelerates breast cancer metastasis by promoting angiogenesis. Nature 2014;515:130-3.

40 Bonavita E, Gentile S, Rubino M, et al. Ptx3 is an extrinsic oncosuppressor regulating complement-dependent inflammation in cancer. Cell 2015;160:700-14.

41 Zha $\mathrm{H}$, Wang $\mathrm{X}$, Zhu $\mathrm{Y}$, et al. Intracellular activation of complement C3 leads to PD-L1 antibody treatment resistance by modulating tumor-associated macrophages. Cancer Immunol Res 2019;7:193-207.

42 Lesokhin AM, Hohl TM, Kitano S, et al. Monocytic CCR2(+) myeloidderived suppressor cells promote immune escape by limiting activated CD8 T-cell infiltration into the tumor microenvironment. Cancer Res 2012;72:876-86.

43 Li X, Yao W, Yuan Y, et al. Targeting of tumour-infiltrating macrophages via CCL2/CCR2 signalling as a therapeutic strategy against hepatocellular carcinoma. Gut 2017;66:157-67.

44 Qian B-Z, Li J, Zhang H, et al. Ccl2 recruits inflammatory monocytes to facilitate breast-tumour metastasis. Nature 2011;475:222-5.

45 Zhu Y, Herndon JM, Sojka DK, et al. Tissue-Resident macrophages in pancreatic ductal adenocarcinoma originate from embryonic hematopoiesis and promote tumor progression. Immunity 2017;47:323-38.

46 Pollard JW. The yolk sac feeds pancreatic tumors. Immunity 2017;47:217-8

47 Ajami B, Bennett JL, Krieger C, et al. Local self-renewal can sustain CNS microglia maintenance and function throughout adult life. Nat Neurosci 2007;10:1538-43.

48 Ginhoux F, Greter M, Leboeuf M, et al. Fate mapping analysis reveals that adult microglia derive from primitive macrophages. Science 2010;330:841-5.

49 Goldmann T, Wieghofer P, Jordão MJC, et al. Origin, fate and dynamics of macrophages at central nervous system interfaces. Nat Immunol 2016;17:797-805

50 Gomez Perdiguero E, Klapproth K, Schulz C, et al. Tissue-resident macrophages originate from yolk-sac-derived erythro-myeloid progenitors. Nature 2015;518:547-51.

51 Cassetta L, Fragkogianni S, Sims AH, et al. Human tumorassociated macrophage and monocyte transcriptional landscapes reveal cancer-specific reprogramming, biomarkers, and therapeutic targets. Cancer Cell 2019;35:588-602.

52 Cassetta L, Pollard JW. Tumor-associated macrophages. Curr Biol 2020;30:R246-8.

53 Loyher P-L, Hamon P, Laviron M, et al. Macrophages of distinct origins contribute to tumor development in the lung. $J$ Exp Med 2018;215:2536-53.

54 Bianchi ME, Crippa MP, Manfredi AA, et al. High-mobility group box 1 protein orchestrates responses to tissue damage via inflammation, innate and adaptive immunity, and tissue repair. Immunol Rev 2017;280:74-82.

55 Muldoon JJ, Chuang Y, Bagheri N, et al. Macrophages employ quorum licensing to regulate collective activation. Nat Commun 2020;11:878.

56 Tellechea M, Buxadé M, Tejedor S, et al. NFAT5-Regulated macrophage polarization supports the proinflammatory function of macrophages and T lymphocytes. J Immunol 2018;200:305-15.

57 Huerga Encabo H, Traveset L, Argilaguet J, et al. The transcription factor NFAT5 limits infection-induced type I interferon responses. $J$ Exp Med 2020;217. doi:10.1084/jem.20190449. [Epub ahead of print: 02 Mar 2020] 
58 Rhee AJ, Lavine KJ. New approaches to target inflammation in heart failure: harnessing insights from studies of immune cell diversity. Annu Rev Physiol 2020;82:1-20.

59 Raggi F, Pelassa S, Pierobon D, et al. Regulation of human macrophage M1-M2 polarization balance by hypoxia and the triggering receptor expressed on myeloid cells-1. Front Immunol 2017;8:1097.

60 Zhou H, Wang H, Ni M, et al. Glycogen synthase kinase $3 \beta$ promotes liver innate immune activation by restraining AMP activated protein kinase activation. J Hepatol 2018;69:99-109.

61 Gordon S, Martinez FO. Alternative activation of macrophages: mechanism and functions. Immunity 2010;32:593-604.

62 Jaynes JM, Sable R, Ronzetti M, et al. Mannose receptor (CD206) activation in tumor-associated macrophages enhances adaptive and innate antitumor immune responses. Sci Trans/ Med 2020;12:eaax6337.

63 Gharib SA, McMahan RS, Eddy WE, et al. Transcriptional and functional diversity of human macrophage repolarization. J Allergy Clin Immunol 2019;143:1536-48.

64 Fan J-Q, Wang M-F, Chen H-L, et al. Current advances and outlooks in immunotherapy for pancreatic ductal adenocarcinoma. Mol Cancer 2020;19:32.

65 Barros MHM, Hauck F, Dreyer JH, et al. Macrophage polarisation: an immunohistochemical approach for identifying M1 and M2 macrophages. PLoS One 2013;8:e80908.

66 Liu M, Tong Z, Ding C, et al. Transcription factor c-Maf is a checkpoint that programs macrophages in lung cancer. J Clin Invest 2020;130:2081-96.

67 Dusoswa SA, Verhoeff J, Abels E, et al. Glioblastomas exploit truncated O-linked glycans for local and distant immune modulation via the macrophage galactose-type lectin. Proc Natl Acad Sci U S A 2020;117:3693-703.

68 Zhao P, Gao D, Wang Q, et al. Response gene to complement 32 (RGC-32) expression on M2-polarized and tumor-associated macrophages is M-CSF-dependent and enhanced by tumor-derived IL-4. Cell Mol Immunol 2015;12:692-9.

69 Röszer T. Understanding the mysterious M2 macrophage through activation markers and effector mechanisms. Mediators Inflamm 2015;2015:1-16.

70 Stempin CC, Dulgerian LR, Garrido VV, et al. Arginase in parasitic infections: macrophage activation, immunosuppression, and intracellular signals. J Biomed Biotechnol 2010;2010:1-10.

71 Liu Y-C, Zou X-B, Chai Y-F, et al. Macrophage polarization in inflammatory diseases. Int J Biol Sci 2014;10:520-9.

72 Madsen DH, Jürgensen HJ, Siersbæk MS, et al. Tumorassociated macrophages derived from circulating inflammatory monocytes degrade collagen through cellular uptake. Cell Rep 2017;21:3662-71.

73 Arwert EN, Harney AS, Entenberg D, et al. A unidirectional transition from migratory to perivascular macrophage is required for tumor cell intravasation. Cell Rep 2018;23:1239-48.

74 Nywening TM, Belt BA, Cullinan DR, et al. Targeting both tumourassociated $\mathrm{CXCR}^{+}$neutrophils and $\mathrm{CCR} 2^{+}$macrophages disrupts myeloid recruitment and improves chemotherapeutic responses in pancreatic ductal adenocarcinoma. Gut 2018;67:1112-23.

75 Sica A, Schioppa T, Mantovani A, et al. Tumour-associated macrophages are a distinct M2 polarised population promoting tumour progression: potential targets of anti-cancer therapy. Eur J Cancer 2006;42:717-27.

76 Chen Y, Song Y, Du W, et al. Tumor-associated macrophages: an accomplice in solid tumor progression. J Biomed Sci 2019;26:78.

77 Lin Y, Xu J, Lan H. Tumor-associated macrophages in tumor metastasis: biological roles and clinical therapeutic applications. J Hematol Oncol 2019;12:76.

78 Movahedi K, Laoui D, Gysemans C, et al. Different tumor microenvironments contain functionally distinct subsets of macrophages derived from Ly6C(high) monocytes. Cancer Res 2010;70:5728-39.

79 Obeid E, Nanda R, Fu Y-X, et al. The role of tumor-associated macrophages in breast cancer progression (review). Int $\mathrm{J}$ Oncol 2013;43:5-12

80 Ye Y-C, Zhao J-L, Lu Y-T, YC Y, YT L, et al. Notch signaling via Wnt regulates the proliferation of alternative, CCR2-Independent tumorassociated macrophages in hepatocellular carcinoma. Cancer Res 2019;79:4160-72.

81 Shen Q, Cohen B, Zheng W, et al. Notch shapes the innate immunophenotype in breast cancer. Cancer Discov 2017;7:1320-35.

82 Yu-Ju Wu C, Chen C-H, Lin C-Y, et al. Ccl5 of glioma-associated microglia/macrophages regulates glioma migration and invasion via calcium-dependent matrix metalloproteinase 2. Neuro Oncol 2020;22:253-66.

83 Zhao S-J, Kong F-Q, Jie J, et al. Macrophage MSR1 promotes BMSC osteogenic differentiation and M2-like polarization by activating PI3K/AKT/GSK3 $\beta / \beta$-catenin pathway. Theranostics 2020;10:17-35.

84 Halbrook CJ, Pontious C, Kovalenko I, et al. Macrophage-released pyrimidines inhibit gemcitabine therapy in pancreatic cancer. Cell Metab 2019;29:1390-9.

85 Mantovani A, Marchesi F, Malesci A, et al. Tumour-associated macrophages as treatment targets in oncology. Nat Rev Clin Oncol 2017; 14:399-416.

86 Franklin RA, Li MO. Ontogeny of tumor-associated macrophages and its implication in cancer regulation. Trends Cancer 2016;2:20-34

87 Taniyama D, Taniyama K, Kuraoka K, et al. Long-term follow-up study of gastric adenoma; tumor-associated macrophages are associated to carcinoma development in gastric adenoma. Gastric Cancer 2017;20:929-39.

88 Gomes FG, Nedel F, Alves AM, et al. Tumor angiogenesis and lymphangiogenesis: tumor/endothelial crosstalk and cellular/ microenvironmental signaling mechanisms. Life Sci 2013;92:101-7.

89 Janssen LME, Ramsay EE, Logsdon CD, et al. The immune system in cancer metastasis: friend or foe? J Immunother Cancer 2017;5:79.

90 Ruffell B, Affara NI, Coussens LM. Differential macrophage programming in the tumor microenvironment. Trends Immunol 2012;33:119-26.

91 Imtiyaz HZ, Simon MC. Hypoxia-inducible factors as essential regulators of inflammation. Curr Top Microbiol Immunol 2010;345:105-20.

92 Yang L, Zhang Y. Tumor-associated macrophages: from basic research to clinical application. J Hematol Oncol 2017;10:58.

93 Han Y, Guo W, Ren T, et al. Tumor-associated macrophages promote lung metastasis and induce epithelial-mesenchymal transition in osteosarcoma by activating the COX-2/STAT3 axis. Cancer Lett 2019;440-441:116-25.

94 Binnewies M, Roberts EW, Kersten K, et al. Understanding the tumor immune microenvironment (time) for effective therapy. Nat Med 2018;24:541-50.

95 Beatty GL, Gladney WL. Immune escape mechanisms as a guide for cancer immunotherapy. Clin Cancer Res 2015;21:687-92.

96 Capece D, Fischietti M, Verzella D, et al. The inflammatory microenvironment in hepatocellular carcinoma: a pivotal role for tumor-associated macrophages. Biomed Res Int 2013;2013:1-15.

97 Ren B, Cui M, Yang G, et al. Tumor microenvironment participates in metastasis of pancreatic cancer. Mol Cancer 2018;17:108.

98 Li C, Jiang P, Wei S, et al. Regulatory T cells in tumor microenvironment: new mechanisms, potential therapeutic strategies and future prospects. Mol Cancer 2020;19:116.

99 Missiaen R, Mazzone M, Bergers G. The reciprocal function and regulation of tumor vessels and immune cells offers new therapeutic opportunities in cancer. Semin Cancer Biol 2018;52:107-16.

100 Rodriguez PC, Quiceno DG, Zabaleta J, et al. Arginase I production in the tumor microenvironment by mature myeloid cells inhibits T-cell receptor expression and antigen-specific T-cell responses. Cancer Res 2004;64:5839-49.

101 Chen G-Y, Tang J, Zheng P, et al. CD24 and Siglec-10 selectively repress tissue damage-induced immune responses. Science 2009;323:1722-5

102 Sammar M, Siwetz M, Meiri H, et al. Expression of CD24 and Siglec-10 in first trimester placenta: implications for immune tolerance at the fetal-maternal interface. Histochem Cell Biol 2017;147:565-74.

103 Barkal AA, Brewer RE, Markovic M, et al. CD24 signalling through macrophage Siglec-10 is a target for cancer immunotherapy. Nature 2019:572:392-6.

104 Malesci A, Bianchi P, Celesti G, et al. Tumor-associated macrophages and response to 5-fluorouracil adjuvant therapy in stage III colorectal cancer. Oncoimmunology 2017;6:e1342918.

105 Bercovici N, Guérin MV, Trautmann A, et al. The remarkable plasticity of macrophages: a chance to fight cancer. Front Immunol 2019;10:1563.

106 Lelios I, Cansever D, Utz SG, et al. Emerging roles of IL-34 in health and disease. J Exp Med 2020;217. doi:10.1084/jem.20190290. [Epub ahead of print: 02 Mar 2020].

107 Papadopoulos KP, Gluck L, Martin LP, et al. First-In-Human study of AMG 820, a monoclonal Anti-Colony-Stimulating factor 1 receptor antibody, in patients with advanced solid tumors. Clin Cancer Res 2017:23:5703-10. 
108 Yeh Y-M, Hsu S-J, Lin P-C, et al. The c.1085A>G genetic variant of $C S F 1 R$ gene regulates tumor immunity by altering the proliferation, polarization, and function of macrophages. Clin Cancer Res 2017:23:6021-30.

109 Webb MW, Sun J, Sheard MA, et al. Colony stimulating factor 1 receptor blockade improves the efficacy of chemotherapy against human neuroblastoma in the absence of T lymphocytes. Int $J$ Cancer 2018;143:1483-93.

110 Pradel LP, Ooi C-H, Romagnoli S, et al. Macrophage susceptibility to Emactuzumab (RG7155) treatment. Mol Cancer Ther 2016;15:3077-86

111 Zhu Y, Knolhoff BL, Meyer MA, et al. CSF1/CSF1R blockade reprograms tumor-infiltrating macrophages and improves response to T-cell checkpoint immunotherapy in pancreatic cancer models. Cancer Res 2014;74:5057-69.

112 Neubert NJ, Schmittnaegel M, Bordry N, et al. T cell-induced CSF1 promotes melanoma resistance to PD1 blockade. Sci Transl Med 2018;10:eaan3311.

113 Kumar V, Donthireddy L, Marvel D, et al. Cancer-associated fibroblasts neutralize the anti-tumor effect of CSF1 receptor blockade by inducing PMN-MDSC infiltration of tumors. Cancer Cell 2017;32:654-68.

114 Edwards DK, Watanabe-Smith K, Rofelty A, et al. CSF1R inhibitors exhibit antitumor activity in acute myeloid leukemia by blocking paracrine signals from support cells. Blood 2019;133:588-99.

115 Kalbasi A, Komar C, Tooker GM, et al. Tumor-derived CCL2 mediates resistance to radiotherapy in pancreatic ductal adenocarcinoma. Clin Cancer Res 2017;23:137-48.

116 Walens A, DiMarco AV, Lupo R, et al. CCL5 promotes breast cancer recurrence through macrophage recruitment in residual tumors. Elife 2019;8. doi:10.7554/eLife.43653. [Epub ahead of print: 16 Apr 2019].

117 Liu C, Yao Z, Wang J, et al. Macrophage-derived CCL 5 facilitates immune escape of colorectal cancer cells via the p65/STAT3-CSN5PD-L1 pathway. Cell Death Differ 2020;27:1765-81.

118 Zeisberger SM, Odermatt B, Marty C, et al. Clodronate-liposomemediated depletion of tumour-associated macrophages: a new and highly effective antiangiogenic therapy approach. $\mathrm{Br} J$ Cancer 2006;95:272-81.

119 Piaggio F, Kondylis V, Pastorino F, et al. A novel liposomal clodronate depletes tumor-associated macrophages in primary and metastatic melanoma: anti-angiogenic and anti-tumor effects. $J$ Control Release 2016;223:165-77.

120 Jeong H, Kim S, Hong B-J, et al. Tumor-associated macrophages enhance tumor hypoxia and aerobic glycolysis. Cancer Res 2019;79:canres.2545.2018-806.

121 Foubert P, Kaneda MM, Varner JA. PI3K $\gamma$ activates integrin $\alpha_{4}$ and promotes immune suppressive myeloid cell polarization during tumor progression. Cancer Immunol Res 2017:5:957-68.

122 Horwitz SM, Koch R, Porcu P, et al. Activity of the PI3K- $\delta, \gamma$ inhibitor duvelisib in a phase 1 trial and preclinical models of T-cell lymphoma. Blood 2018;131:888-98.

123 Pushalkar S, Hundeyin M, Daley D, et al. The pancreatic cancer microbiome promotes oncogenesis by induction of innate and adaptive immune suppression. Cancer Discov 2018;8:403-16.

124 Takeda AJ, Maher TJ, Zhang Y, et al. Human PI3K $\gamma$ deficiency and its microbiota-dependent mouse model reveal immunodeficiency and tissue immunopathology. Nat Commun 2019;10:4364.

125 Qin H, Yu H, Sheng J, et al. PI3Kgamma inhibitor attenuates immunosuppressive effect of poly(I -Glutamic Acid)Combretastatin A4 conjugate in metastatic breast cancer. Adv Sci 2019;6:1900327

126 Zeng Q, Jewell CM. Directing Toll-like receptor signaling in macrophages to enhance tumor immunotherapy. Curr Opin Biotechnol 2019;60:138-45.

127 Vidyarthi A, Khan N, Agnihotri T, et al. Tlr-3 stimulation skews M2 macrophages to M1 through IFN- $\alpha \beta$ signaling and restricts tumor progression. Front Immunol 2018;9:1650.

128 Zheng JH, Nguyen VH, Jiang S-N, et al. Two-step enhanced cance immunotherapy with engineered Salmonella typhimurium secreting heterologous flagellin. Sci Transl Med 2017;9:eaak9537.

129 Li R, Zhou R, Wang H, et al. Gut microbiota-stimulated cathepsin K secretion mediates TLR4-dependent M2 macrophage polarization and promotes tumor metastasis in colorectal cancer. Cell Death Differ 2019:26:2447-63.

130 Ubil E, Caskey L, Holtzhausen A, et al. Tumor-Secreted PROS1 inhibits macrophage M1 polarization to reduce antitumor immune response. J Clin Invest 2018;128:2356-69.

131 Beatty GL, Chiorean EG, Fishman MP, et al. Cd40 agonists alter tumor stroma and show efficacy against pancreatic carcinoma in mice and humans. Science 2011;331:1612-6.
132 Wiehagen KR, Girgis NM, Yamada DH, et al. Combination of CD40 agonism and CSF-1R blockade Reconditions tumor-associated macrophages and drives potent antitumor immunity. Cancer Immunol Res 2017;5:1109-21.

133 Perry CJ, Muñoz-Rojas AR, Meeth KM, et al. Myeloid-targeted immunotherapies act in synergy to induce inflammation and antitumor immunity. J Exp Med 2018;215:877-93.

134 Hoves S, Ooi C-H, Wolter C, et al. Rapid activation of tumorassociated macrophages boosts preexisting tumor immunity. J Exp Med 2018;215:859-76.

135 Zhang JQ, Zeng S, Vitiello GA, et al. Macrophages and CD8 ${ }^{+} \mathrm{T}$ cells mediate the antitumor efficacy of combined CD40 ligation and imatinib therapy in gastrointestinal stromal tumors. Cancer Immunol Res 2018;6:434-47.

136 Anglicheau D, Muthukumar T, Suthanthiran M. Micrornas: small RNAs with big effects. Transplantation Journal 2010;90:105-12.

$137 \mathrm{Wu} \mathrm{H}, \mathrm{Ye} \mathrm{C}$, Ramirez D, et al. Alternative processing of primary microRNA transcripts by Drosha generates $5^{\prime}$ end variation of mature microRNA. PLoS One 2009;4:e7566.

138 Boeri M, Milione M, Proto C, et al. Circulating miRNAs and PD-L1 tumor expression are associated with survival in advanced NSCLC patients treated with immunotherapy: a prospective study. Clin Cancer Res 2019;25:2166-73.

$139 \mathrm{Xi} \mathrm{J}$, Huang Q, Wang L, et al. miR-21 depletion in macrophages promotes tumoricidal polarization and enhances PD-1 immunotherapy. Oncogene 2018;37:3151-65.

140 Zhu Y, Gu L, Li Y, et al. miR-148A inhibits colitis and colitis-associated tumorigenesis in mice. Cell Death Differ 2017;24:2199-209.

141 Yin Y, Yao S, Hu Y, et al. The Immune-microenvironment confers chemoresistance of colorectal cancer through macrophage-derived IL6. Clin Cancer Res 2017;23:7375-87.

142 Cooks T, Pateras IS, Jenkins LM, et al. Mutant p53 cancers reprogram macrophages to tumor supporting macrophages via exosomal miR-1246. Nat Commun 2018;9:771.

143 Lan J, Sun L, Xu F, et al. M2 macrophage-derived exosomes promote cell migration and invasion in colon cancer. Cancer Res 2019;79:146-58.

144 Huffaker TB, Lee S-H, Tang WW, et al. Antitumor immunity is defective in T cell-specific microRNA-155-deficient mice and is rescued by immune checkpoint blockade. J Biol Chem 2017;292:18530-41.

145 O'Connell RM, Taganov KD, Boldin MP, et al. Microrna-155 is induced during the macrophage inflammatory response. Proc Natl Acad Sci U S A 2007;104:1604-9.

146 Sánchez-González I, Bobien A, Molnar C, et al. miR-149 suppresses breast cancer metastasis by blocking paracrine interactions with macrophages. Cancer Res 2020;80:1330-41.

147 Wang X, Luo G, Zhang K, et al. Hypoxic tumor-derived exosomal miR-301a mediates M2 macrophage polarization via PTEN/ $\mathrm{PI} 3 \mathrm{~K} \gamma$ to promote pancreatic cancer metastasis. Cancer Res 2018;78:4586-98.

148 Hsu Y-L, Hung J-Y, Chang W-A, et al. Hypoxic Lung-CancerDerived extracellular vesicle MicroRNA-103a increases the oncogenic effects of macrophages by targeting PTEN. Mol Ther 2018;26:568-81.

149 Lin X, Wang S, Sun M, et al. miR-195-5p/NOTCH2-mediated EMT modulates IL-4 secretion in colorectal cancer to affect M2-like TAM polarization. J Hematol Oncol 2019;12:20.

150 Pirruccello SJ, LeBien TW. The human B cell-associated antigen CD24 is a single chain sialoglycoprotein. $J$ Immunol 1986;136:3779-84.

151 Bradley CA. CD24 - a novel 'don't eat me' signal. Nat Rev Cancer 2019;19:541.

152 Chen W, Han C, Xie B, et al. Induction of Siglec-G by RNA viruses inhibits the innate immune response by promoting RIG-I degradation. Cell 2013;152:467-78.

153 Chen G-Y, Chen X, King S, et al. Amelioration of sepsis by inhibiting sialidase-mediated disruption of the CD24-SiglecG interaction. Nat Biotechnol 2011;29:428-35.

154 American Association for Cancer Research. CD24 Is a "don't eat me" signal that promotes tumor immune escape. Cancer Discov 2019;9:1156.

155 Feng M, Jiang W, Kim BYS, et al. Phagocytosis checkpoints as new targets for cancer immunotherapy. Nat Rev Cancer 2019;19:568-86.

156 Jaiswal S, Jamieson CHM, Pang WW, et al. Cd47 is upregulated on circulating hematopoietic stem cells and leukemia cells to avoid phagocytosis. Cell 2009;138:271-85.

157 Chao MP, Tang C, Pachynski RK, et al. Extranodal dissemination of non-Hodgkin lymphoma requires CD47 and is inhibited by antiCD47 antibody therapy. Blood 2011;118:4890-901. 
158 Weiskopf K, Ring AM, Ho CCM, et al. Engineered SIRP $\alpha$ variants as immunotherapeutic adjuvants to anticancer antibodies. Science 2013;341:88-91.

159 Pan Y, Lu F, Fei Q, et al. Single-cell RNA sequencing reveals compartmental remodeling of tumor-infiltrating immune cells induced by anti-CD47 targeting in pancreatic cancer. J Hematol Oncol 2019;12:124.

160 Betancur PA, Abraham BJ, Yiu YY, et al. A CD47-associated superenhancer links pro-inflammatory signalling to CD47 upregulation in breast cancer. Nat Commun 2017;8:14802.

161 Koh E, Lee EJ, Nam G-H, et al. Exosome-SIRP $\alpha$, a CD47 blockade increases cancer cell phagocytosis. Biomaterials 2017;121:121-9.

162 Chen Y-P, Kim HJ, Wu H, et al. Sirpo expression delineates subsets of intratumoral monocyte/macrophages with different functional and prognostic impact in follicular lymphoma. Blood Cancer $J$ 2019;9:84

163 Ring NG, Herndler-Brandstetter D, Weiskopf K, et al. Anti-SIRP $\alpha$ antibody immunotherapy enhances neutrophil and macrophage antitumor activity. Proc Natl Acad Sci U S A 2017;114:E10578-85.

164 de Silva S, Fromm G, Shuptrine CW, et al. Cd40 enhances type I interferon responses downstream of CD47 blockade, bridging innate and adaptive immunity. Cancer Immunol Res 2020;8:230-45.

165 Barkal AA, Weiskopf K, Kao KS, et al. Engagement of MHC class I by the inhibitory receptor LILRB1 suppresses macrophages and is a target of cancer immunotherapy. Nat Immunol 2018;19:76-84.

166 Nie W, Wu G, Zhang J, et al. Responsive exosome Nanobioconjugates for synergistic cancer therapy. Angew Chem Int Ed Engl 2020;59:2018-22.

167 Jain S, Van Scoyk A, Morgan EA, et al. Targeted inhibition of CD47$\mathrm{SIRP} \alpha$ requires $\mathrm{Fc}-\mathrm{Fc} \gamma \mathrm{R}$ interactions to maximize activity in T-cell lymphomas. Blood 2019;134:1430-40.

168 Logtenberg MEW, Jansen JHM, Raaben M, et al. Glutaminyl cyclase is an enzymatic modifier of the CD47- SIRP $\alpha$ axis and a target for cancer immunotherapy. Nat Med 2019;25:612-9.

169 Majeti R, Chao MP, Alizadeh AA, et al. Cd47 is an adverse prognostic factor and therapeutic antibody target on human acute myeloid leukemia stem cells. Cell 2009;138:286-99.

170 Petrova PS, Viller NN, Wong M, et al. TTI-621 (SIRP $\alpha F c)$ : a CD47-Blocking innate immune checkpoint inhibitor with broad antitumor activity and minimal erythrocyte binding. Clin Cancer Res 2017;23:1068-79.

171 Tseng D, Volkmer J-P, Willingham SB, et al. Anti-CD47 antibodymediated phagocytosis of cancer by macrophages primes an effective antitumor T-cell response. Proc Natl Acad Sci U S A 2013;110:11103-8.

172 Yang X, Feng W, Wang R, et al. Repolarizing heterogeneous leukemia-associated macrophages with more M1 characteristics eliminates their pro-leukemic effects. Oncoimmunology 2018;7:e1412910.

173 Kiss B, van den Berg NS, Ertsey R, et al. CD47-Targeted nearinfrared photoimmunotherapy for human bladder cancer. Clin Cancer Res 2019;25:3561-71.

174 Chan KS, Espinosa I, Chao M, et al. Identification, molecular characterization, clinical prognosis, and therapeutic targeting of human bladder tumor-initiating cells. Proc Natl Acad Sci U S A 2009;106:14016-21.

175 Chao MP, Alizadeh AA, Tang C, et al. Therapeutic antibody targeting of CD47 eliminates human acute lymphoblastic leukemia. Cancer Res 2011;71:1374-84.

176 Chao MP, Alizadeh AA, Tang C, et al. Anti-CD47 antibody synergizes with rituximab to promote phagocytosis and eradicate non-Hodgkin lymphoma. Cell 2010;142:699-713.

177 Weiskopf K, Anderson KL, Ito D, et al. Eradication of canine diffuse large B-cell lymphoma in a murine xenograft model with CD47 blockade and anti-CD20. Cancer Immunol Res 2016;4:1072-87.

178 Gholamin S, Mitra SS, Feroze AH, et al. Disrupting the CD47SIRP $\alpha$ anti-phagocytic axis by a humanized anti-CD47 antibody is an efficacious treatment for malignant pediatric brain tumors. Sci Trans/ Med 2017;9:eaaf2968.

179 Advani R, Flinn I, Popplewell L, et al. CD47 Blockade by Hu5F9-G4 and Rituximab in Non-Hodgkin's Lymphoma. N Engl J Med Overseas Ed 2018;379:1711-21.

180 Sikic BI, Lakhani N, Patnaik A, et al. First-In-Human, first-in-class phase I trial of the Anti-CD47 antibody Hu5F9-G4 in patients with advanced cancers. J Clin Oncol 2019:37:946-53.

181 Hutter G, Theruvath J, Graef CM, et al. Microglia are effector cells of CD47-SIRP $\alpha$ antiphagocytic axis disruption against glioblastoma. Proc Natl Acad Sci U S A 2019;116:997-1006.

182 Chao MP, Jaiswal S, Weissman-Tsukamoto R, et al. Calreticulin is the dominant pro-phagocytic signal on multiple human cancers and is counterbalanced by CD47. Sci Transl Med 2010;2:63ra94.
183 Feng M, Chen JY, Weissman-Tsukamoto R, et al. Macrophages eat cancer cells using their own calreticulin as a guide: roles of TLR and Btk. Proc Natl Acad Sci U S A 2015;112:2145-50.

184 Sprinzl MF, Puschnik A, Schlitter AM, et al. Sorafenib inhibits macrophage-induced growth of hepatoma cells by interference with insulin-like growth factor-1 secretion. J Hepatol 2015;62:863-70.

185 Hage C, Hoves S, Strauss L, et al. Sorafenib induces pyroptosis in macrophages and triggers natural killer cell-mediated cytotoxicity against hepatocellular carcinoma. Hepatology 2019;70:1280-97.

186 Ireland L, Santos A, Campbell F, et al. Blockade of insulin-like growth factors increases efficacy of paclitaxel in metastatic breast cancer. Oncogene 2018;37:2022-36.

187 Du L, Lin L, Li Q, et al. Igf-2 Preprograms maturing macrophages to acquire oxidative phosphorylation-dependent anti-inflammatory properties. Cell Metab 2019;29:1363-75.

188 Lee J, Liao R, Wang G, et al. Preventive inhibition of liver tumorigenesis by systemic activation of innate immune functions. Cell Rep 2017;21:1870-82.

189 Alaeddine M, Prat M, Poinsot V, et al. IL13-Mediated Dectin-1 and mannose receptor overexpression promotes macrophage antitumor activities through recognition of sialylated tumor cells. Cancer Immunol Res 2019;7:321-34.

190 Tariq M, Zhang J-Q, Liang G-K, et al. Gefitinib inhibits M2-like polarization of tumor-associated macrophages in Lewis lung cancer by targeting the STAT6 signaling pathway. Acta Pharmacol Sin 2017:38:1501-11.

191 Zhang Q, Li Y, Miao C, et al. Anti-Angiogenesis effect of neferine via regulating autophagy and polarization of tumor-associated macrophages in high-grade serous ovarian carcinoma. Cancer Lett 2018;432:144-55.

192 Martínez VG, Rubio C, Martínez-Fernández M, et al. Bmp4 induces M2 macrophage polarization and favors tumor progression in bladder cancer. Clin Cancer Res 2017;23:7388-99.

193 Liu Q, Tong D, Liu G, et al. Metformin inhibits prostate cancer progression by targeting tumor-associated inflammatory infiltration. Clin Cancer Res 2018;24:5622-34.

194 Kou Y, Ji L, Wang H, et al. Connexin 43 upregulation by dioscin inhibits melanoma progression via suppressing malignancy and inducing M1 polarization. Int J Cancer 2017;141:1690-703.

195 Tan B, Shi X, Zhang J, et al. Inhibition of Rspo-Lgr4 facilitates checkpoint blockade therapy by switching macrophage polarization. Cancer Res 2018;78:4929-42.

196 Huang H, Wang C, Liu F, et al. Reciprocal network between cancer stem-like cells and macrophages facilitates the progression and androgen deprivation therapy resistance of prostate cancer. Clin Cancer Res 2018;24:4612-26.

197 Jing B, Wang T, Sun B, et al. IL6/STAT3 signaling orchestrates Premetastatic niche formation and immunosuppressive traits in lung. Cancer Res 2020;80:784-97.

198 Poh AR, Dwyer AR, Eissmann MF, et al. Inhibition of the Src kinase Hck impairs STAT3-dependent gastric tumor growth in mice. Cancer Immunol Res 2020;8:428-35.

199 Giurisato E, Xu Q, Lonardi S, et al. Myeloid ERK5 deficiency suppresses tumor growth by blocking protumor macrophage polarization via STAT3 inhibition. Proc Natl Acad Sci U S A 2018;115:E2801-10.

200 Chen D, Xie J, Fiskesund R, et al. Chloroquine modulates antitumor immune response by resetting tumor-associated macrophages toward M1 phenotype. Nat Commun 2018;9:873.

201 Brenot A, Knolhoff BL, DeNardo DG, et al. Snail1 action in tumor cells influences macrophage polarization and metastasis in breast cancer through altered GM-CSF secretion. Oncogenesis 2018;7:32.

202 Li F, Huang Q, Luster TA, et al. In Vivo Epigenetic CRISPR Screen Identifies Asf1a as an Immunotherapeutic Target in Kras-Mutant Lung Adenocarcinoma. Cancer Discov 2020;10:270-87.

203 Suarez-Lopez L, Sriram G, Kong YW, et al. Mk2 contributes to tumor progression by promoting M2 macrophage polarization and tumor angiogenesis. Proc Natl Acad Sci U S A 2018;115:E4236-44.

204 Petty AJ, Li A, Wang X, et al. Hedgehog signaling promotes tumorassociated macrophage polarization to suppress intratumoral CD8+ T cell recruitment. J Clin Invest 2019;129:5151-62.

205 Maximov V, Chen Z, Wei Y, et al. Tumour-associated macrophages exhibit anti-tumoural properties in sonic hedgehog medulloblastoma. Nat Commun 2019;10:2410.

206 Kioi M, Vogel H, Schultz G, et al. Inhibition of vasculogenesis, but not angiogenesis, prevents the recurrence of glioblastoma after irradiation in mice. J Clin Invest 2010;120:694-705.

207 Mole RH. Whole body irradiation; radiobiology or medicine? Br J Radiol 1953;26:234-41. 
208 Demaria S, Ng B, Devitt ML, et al. lonizing radiation inhibition of distant untreated tumors (abscopal effect) is immune mediated. Int $J$ Radiat Oncol Biol Phys 2004;58:862-70.

209 Postow MA, Callahan MK, Barker CA, et al. Immunologic correlates of the abscopal effect in a patient with melanoma. N Engl $J$ Med 2012;366:925-31.

210 Du R, Lu KV, Petritsch C, et al. Hif1Alpha induces the recruitment of bone marrow-derived vascular modulatory cells to regulate tumor angiogenesis and invasion. Cancer Cell 2008;13:206-20.

211 Tsai C-S, Chen F-H, Wang C-C, et al. Macrophages from irradiated tumors express higher levels of iNOS, arginase-I and COX-2, and promote tumor growth. Int J Radiat Oncol Biol Phys 2007;68:499-507.
212 Noman MZ, Desantis G, Janji B, et al. Pd-L1 is a novel direct target of HIF- $1 \alpha$, and its blockade under hypoxia enhanced MDSCmediated T cell activation. J Exp Med 2014;211:781-90.

213 Freire-de-Lima CG, Xiao YQ, Gardai SJ, et al. Apoptotic cells, through transforming growth factor-beta, coordinately induce anti-inflammatory and suppress pro-inflammatory eicosanoid and $\mathrm{NO}$ synthesis in murine macrophages. $\mathrm{J}$ Biol Chem 2006;281:38376-84.

214 Chen F-H, Chiang C-S, Wang C-C, et al. Radiotherapy decreases vascular density and causes hypoxia with macrophage aggregation in TRAMP-C1 prostate tumors. Clin Cancer Res 2009;15:1721-9. 